\title{
RETENTION IN THE NONPROFIT INDUSTRY
}

\author{
by \\ Lauren Austin \\ Bachelor of Applied Arts in Creative Advertising, \\ Humber College, 2015
}

\begin{abstract}
A MRP
presented to Ryerson University
\end{abstract}

in partial fulfillment of the

requirements for the degree of

Master of Digital Media

in the Program of

Digital Media

Toronto, Ontario, Canada, 2019

(C) Lauren Austin, 2019 


\section{AUTHOR'S DECLARATION FOR ELECTRONIC SUBMISSION OF A MRP}

I hereby declare that I am the sole author of this MRP. This is a true copy of the MRP, including any required final revisions.

I authorize Ryerson University to lend this MRP to other institutions or individuals for the purpose of scholarly research.

I further authorize Ryerson University to reproduce this MRP by photocopying or by other means, in total or in part, at the request of other institutions or individuals for the purpose of scholarly research.

I understand that my MRP may be made electronically available to the public.

FINDING A DIGITAL SOLUTION TO HELP IMPROVE DONOR LIFETIME VALUE AND RETENTION IN THE NONPROFIT INDUSTRY 


\author{
Lauren Austin \\ Master of Digital Media \\ Digital Media \\ Ryerson University, 2019
}

\begin{abstract}
It is commonly understood that attracting a new donor is costlier than investing in an existing relationship. Yet, for the past 12 years the nonprofit industry has relied mostly on new donors while losing more than half of their existing donor base every year. This is an increasingly concerning trend within the nonprofit industry. With the donor base in Canada continuing to age and shrink, nonprofits are facing the need to reach and retain a new group of donors largely unhappy with the way they are being engaged, or not engaged, by nonprofit organizations. Using the Lean Startup methodology, in combination with Customer Discovery research techniques, this project uncovers the common challenges and barriers preventing organizations from improving retention of donors, and arrives at a solution to help address some of these common challenges and barriers.
\end{abstract}

\title{
Acknowledgements
}

I need to thank all 27 participants who more than generously gave their scarce time, attention and experience to this project, I wouldn't have this research without them. I also need to thank my second reader, Jennifer MacInnis, who always encouraged me and helped me move forward. Finally, I need to thank my academic 
supervisor, Dr. Sean Wise, who guided me through the process of tackling a problem of this size and helped shape the strategy of every step so that each was tangible and achievable.

\section{Dedication}

To those who support me as I take on big and complex problems, and all the inspiring, resilient and strong people I've met along the way who have moved me to walk this path. 


\section{Table of Contents}

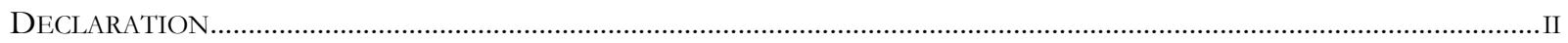

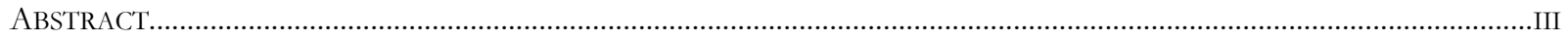

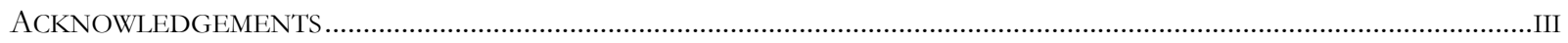

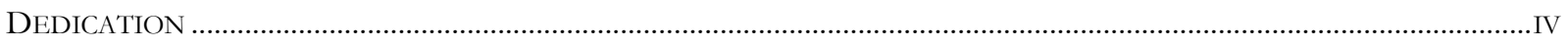

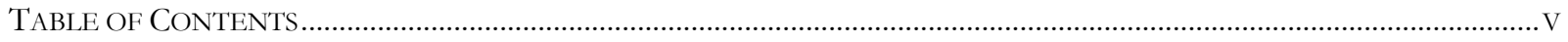

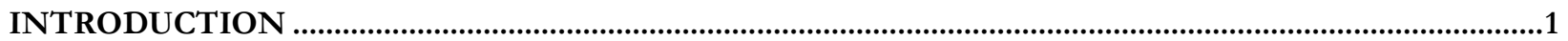

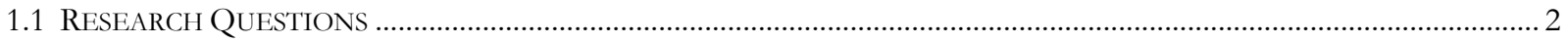

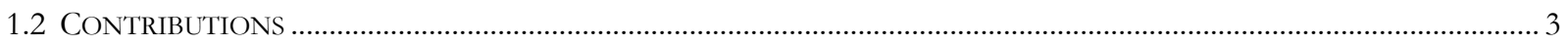

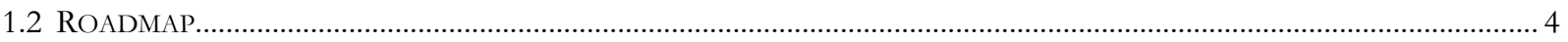

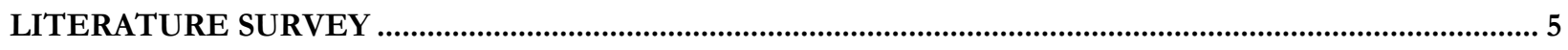

2.1 CONCERNING GIVING TRENDS AND THE IMPORTANCE OF RETENTION .............................................................. 5 
2.1 ReSEARCH OUtLINES Best-Practices IN IMPROVING DONOR RELATIONSHIPS ..................................................

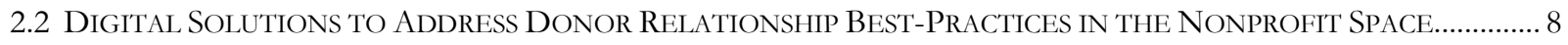

2.3 LEARNINGS FROM CUSTOMER EXPERIENCE AND INSIGHT STRATEGY IN THE For-Profit SPACE ....................... 11

METHODOLOGY, IMPLEMENTATION \& EVALUATION ................................................................13

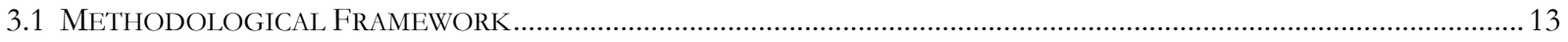

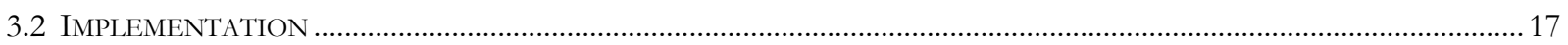

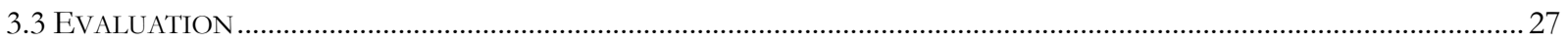

CONCLUSIONS, LIMITATIONS \& FUTURE WORK...........................................................................37

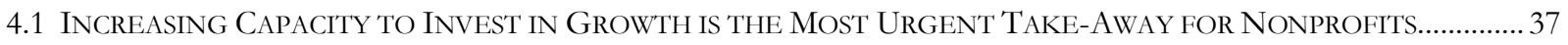

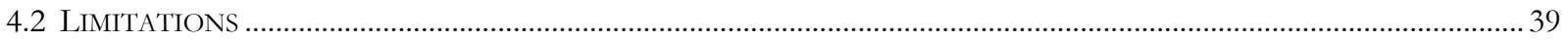

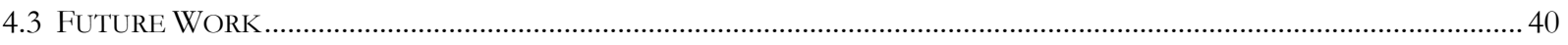

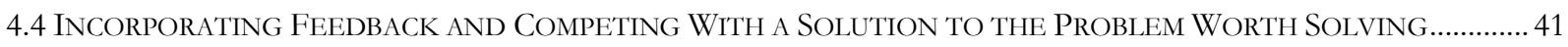

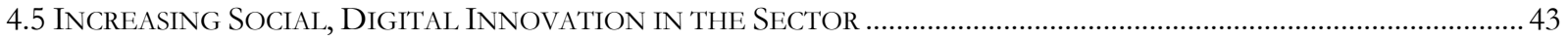

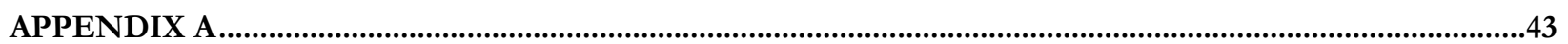

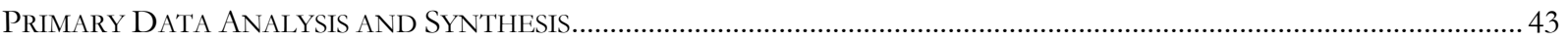

Research Question 1: Given the cost-benefits of improving retention, what are the most common reasons that prevent nonprofits from

relying more on their current donor base for funding? ......................................................................................................43

Research Question 2: Of the most common problems that prevent nonprofits from improving their retention, which are they actively

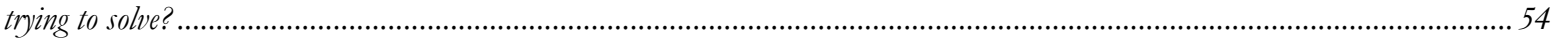

Research Question 3: How can a digital solution help them actively solve common problems surrounding poor retention?..................58

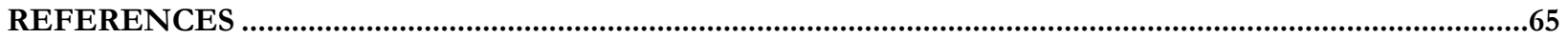




\section{Chapter 1}

\section{Introduction}

Canadians are altruistic people. The charitable giving industry in Canada is the second largest in the world, accounting for more than 8\% of our GDP (Bullard \& Penner, 2017, p.173), and 10\% of full-time jobs (CanadaHelps, 2018, p.2). Since 2006, Canadians have contributed 9-10 billion dollars annually to nonprofits and the essential services they provide (CanadaHelps, 2018, p.3). This industry is consequential, not only for those who form its vital organs and operations, but for all Canadians who want for a better future and, as such, it should be protected.

The relationship between Canadians and nonprofits is symbiotic. Many nonprofits rely on donors as much as Canadians rely on the services nonprofits provide. In less than a decade the nonprofit sector is projected to need an additional $\$ 25$ billion, more than double what they currently generate in support, to meet increasing demand for social services based on demographic trends and average annual growth in GDP (Emmett, 2016). This 'social deficit', as it is called, is predicted to place immense pressure on the government to subsidize social services that will inevitably be affected. This will greatly impact taxpayers, as well as dampen the overall quality of these services, and undermine the equity and quality of life they provide for many (Emmett, 2016). This, in combination with declining giving rates, increased competition, and a shrinking donor base should set an urgent context for the sector to attract and successfully retain new and existing donors. However, nonprofits continue to lose more than half of their donors every year, and are falling short of effectively engaging a new generation of donors. This paper will discuss problems in connection with poor retention and the process that was followed to achieve a viable solution to help improve it. 


\subsection{Research Questions}

This paper endeavors to lay open the challenges and opportunities for Social, digital innovation in the nonprofit sector, specifically surrounding poor retention in a digital context for nonprofits. Continued innovation in this area is essential to keeping nonprofits running at the highest possible standard, and in pace with the for-profit world. It is vital to keeping operations efficient and optimized in order to grow impact sustainably and responsibly, which includes improving donor retention. It will also briefly place these found opportunities and challenges in the context of current, concerning giving trends within Canada. This will be done with the purpose of adding urgency and further context to the arguments presented.

In addition, this paper will describe how the search for 'Problem/Solution Fit', which is the process of finding a viable solution to a viable customer problem (Maurya, 2012), may be used as a methodology to explore within this sector — proposing a tried-and-true framework for innovation in an otherwise difficult and complex market. This method, often referred to as Customer Discovery (Blank, 2012), offers a simple approach to finding a viable problem worth solving for a specific customer segment, test a solution in which to address said problem, and achieve Problem/Solution Fit (Maurya, 2012).

The first phase of Blank and Maurya's methods, Customer Discovery, and Problem/Solution Fit are designed to validate the primary researcher's, or entrepreneur's, initial assumptions and hypotheses (Blank, 2012). By speaking to potential customers, the primary researcher may test their assumptions behind poor retention, in this case, and arrive at problem themes (Blanks, 2012). The second aim of this phase is to "discover" early adopters, or participants actively trying to address the problems surrounding poor retention (Maurya, 2012). These 'early adopters' would therefore be more motivated and most likely to adopt a solution to the problem they are solving in connection to poor retention, as described by Geoffrey Moore who coined this model of technology adoption (Moore, 1999). Once identified, early adopters are validated through a second phase where the primary researcher sets out to discover whether Product/Market Fit is achievable by testing a 
minimum viable product (MVP) with those identified to adopt it (Blank, 2012). Customer validation interviews allow the primary researcher, or entrepreneur, to validate the business model constructed during the Customer Discovery, or Problem/Solution Fit (Maurya, 2012) phase by agreeing to buy or use the MVP (Blank, 2012).

Using these combined methodologies, the following research questions were investigated:

RESEARCH QUESTION 1: Given the ROI of improving retention, what are the most common reasons that prevent nonprofits from relying more on their current donor base for funding?

RESEARCH QUESTION 2: Of the most common problems that prevent nonprofits from improving their retention, which are they actively trying to solve?

RESEARCH QUESTION 3: How can a digital solution help them actively solve common problems surrounding poor retention?

\subsection{Contributions}

"Access to reliable and appropriate evidence is required for evidence-based practice. Yet for the work of [building and maintaining relationships with donors], there is an issue larger than access that must first be addressed: there is a limited volume of research in the field." (Manner-McLarty, 2017, p.8).

This paper contributes to addressing a limited volume of research in this field. Those participants who have supported this paper with their time and lived experience have done so with the expectation that they will gain an understanding of barriers preventing faster growth and healthier retention in their sector. As such, 
this paper intends to deliver on these expectations, barring limitations. Insights and conclusions drawn from the investigation of the first research question will satisfy this promise.

This paper will leverage and illustrate a repeatable, workable framework and proven methodology in which to mine and extract a problem worth solving, and its' viable solution, in this complex sector. This will hopefully leave a well-trodden path for others to provide needed innovation and the latest methods of problem solving to the nonprofit sector in Canada.

Finally, this paper will outline the Problem/Solution Fit that came as a result of implementing this process and discuss its application in increasing a nonprofit's capacity to more effectively build and maintain profitable, longer relationships with their donors, and improve their ability to reach them effectively and efficiently.

\subsection{Roadmap}

Chapter 2 is a survey of literature that provides important background on concerning trends within the nonprofit sector, and best-practices and successful strategy in building an optimal experience and relationship with a donor digitally. It will also touch on current best examples of relationship-building solutions in digital. Chapter 3 will outline the methodology and details on the implementation of the methodology that were used to find Problem/Solution Fit in the context of poor retention. It will provide key findings that address the research questions under investigation, and discuss the solution found. Chapter 4 will provide a summary of findings and next steps in developing Product/Market Fit and Customer Validation as per the methodologies discussed in chapter 3 .

\section{Chapter 2}




\section{Literature Survey}

\subsection{Concerning Giving Trends and the Importance of Retention}

There are more nonprofits in Canada than ever before (CanadaHelps, 2018). With over 86,000 registered charities in Canada (CanadaHelps, 2016), competition for "donor's discretionary income" is tougher than ever — raising demand for low-risk, high-efficiency marketing approaches (Yoo \& Drumwright, 2018, p.12). In addition, the number of nonprofits individuals contribute to per year is declining, along with giving rates (CanadaHelps, 2018, p.3), which is causing an increase in donor attrition (O’Connor, 2016).

"Fundraising charities rarely break even on the initial recruitment of donors, as it usually takes years rather than months to recoup the costs of acquiring new supporters" (Bennett, 2006, p.46). In spite of this, many nonprofits continue to rely on donor acquisition, hoping to make up for an increase in donor attrition and poor retention. According to data from over 13 thousand North American nonprofits covering year-to-year fundraising results from 2016-2017, a majority of income was attributed to new donations and donors (Levis, Miller \& Williams, 2018, p.15-17). In that same period nonprofits lost $\sim 55 \%$ of their donors on average, or 99 donors for every 100 acquired new donors, with smaller nonprofits in the lower $40 \%$ of annual gross revenue reporting net losses in growth due to poor donor retention (Levis et al., 2018, p.15-19).

There is less than a $2 \%$ chance of retaining value from a prospective donor compared to a $60-70 \%$ chance with existing donors, and 20-40\% with lapsed donors (O’Connor, 2016, p.2). Improving a 45\% donor retention by ten percentage points, to 55\%, would double net growth (Levis et al., 2018, p. 6). This is particularly relevant to nonprofits who rely on donors for their sustained growth as many nonprofits continue to lose more donors than they can afford (Levis et al., 2018). These are long standing, increasingly concerning trends within the nonprofit industry, which reinforce the importance of donor-nonprofit relationships as key 
to financial solvency and sustainability. Fundraisers and stewardship professionals are slowly striving to maximize the lifetime giving potential of their donors, but more needs to be done.

As the current donor base in Canada ages and shrinks, nonprofits will need to learn what the next generation of donors expect from their relationships with nonprofits (Lasby \& Barr., 2018). 30 Years of Giving, a study released in 2018 by Rideau Hall and Imagine Canada, draws upon multiple sources such as the Canada Revenue Agency to provide a comprehensive picture of what inhibits and motivates individual giving in Canada (Lasby et al., 2018, p.36). Their findings reveal that 29\% of donors did not give because they feared their money wouldn't be used effectively, or they did not like the way they were asked to give, and $28 \%$ did not give because "no one asked" (Lasby et al., 2018, p.34). A quarter of donors aged 45-65, with a high average gift, were happy with the amount they gave and could have given more, but $30 \%$ did not like the way they were asked to give, were not asked at all, or feared their donations wouldn't be used effectively, and 44\% chose to give directly instead of through an organization (Lasby et al., 2018, p.36). Younger donors aged 1534 , were generally unhappy with the amount they gave and could have given more, but $44 \%$ did not give because they were not asked, 25\% who were asked to give did not like the way they were asked, 34\% felt their donations would not be used effectively, and 25\% did not know where to give (Lasby et al., 2018, p.36).

Clearly, there is a lack of trust and awareness between nonprofits and a new donor base in Canada that has yet to be addressed. Donors are generally unsatisfied with the way nonprofits are soliciting them, have not been effectively engaged by nonprofits, and crave greater transparency with how their contributions are used. Research and investigation into donor values has revealed what should be done to repair this trust. Penelope Burk, a well-respected researcher in this area, has synthesized best-practices into two distinct actions. "Donors want to be thanked promptly for their donations; they want to see their donations designated or assigned to a specific project, or initiative; and they want a report, in measurable terms, on what has been accomplished in that program" without a solicitation (Burk, 2013, p.31). These best-practices in relationshipbuilding are clearly defined, as is their connection to donor satisfaction. However, there still remains a marked 
lack of understanding on how these best-practices alter donor behaviour over time (Manner-McLarty, 2017, p.4).

\subsection{Research Outlines Best-Practices in Improving Donor}

\section{Relationships}

Donor retention is the process whereby effectively communicating the value of the organization's mission and the donor's role in furthering that mission keeps the donor connected, resulting in recurrent contributions (O’Connor, 2016). Understanding donors is fundamental to carrying this process out efficiently and effectively. Organizations have increased their intake of donor information, and more is understood about donor's values and preferences, but this does not often include insight into what program elements are motivating donors (Manner-McLarty, 2017, p.4). Studies have shown that donor-nonprofit identification, on an individual and group level, both increase donor identity salience with an organization, thereby increasing satisfaction, loyalty, and intent to donate (Boenigk et al., 2013). Organizations that do orient their efforts toward building long relationships with their donors have shown an increase in donor-nonprofit identity salience, loyalty, satisfaction, and intention to donate (Boenigk \& Helmig, 2013). These best practices are easier to implement, as well as more effective and efficient, when a nonprofit understands their donors. In other words, when a nonprofit understands their donor's connection to them, and capitalizes on this knowledge, they are much more likely to increase donor loyalty, and bring them closer to the mission and work of the nonprofit.

Additionally, there are general principles of donor psychology which can be followed to communicate more meaningfully on how a donor has impacted the mission. Evidence suggests that closing the psychological distance between a donation and its outcomes is an effective strategy to improve donor satisfaction and, inturn, retention (Merchant, Ford \& Sargeant, 2010). "To improve donor well-being, reduce the psychological distance between the donor's gift and the outcomes brought about by the gift" (Oppenheimer, 2015, p.203). 
Similarly, literature on donor motivations reinforces the importance of maximizing perceived impact through communications and appeals aimed at concretizing the outcomes of a donation (Bullard et al., 2017). Profitable donor relationships hinge on a two-way exchange of value that provides donors access to the organization, vastly improving satisfaction and loyalty (O'Connor, 2016). There is great opportunity with creative content to close the psychological gap between benefactor and beneficiary as a means of reporting to donors, improving perceived transparency and donor satisfaction.

This is, of course, vastly different than appeals aimed at new donors where research suggests that preventionframed messaging, or communicating the need for donor intervention to prevent an unfavourable outcome, is the most effective form of messaging (Bullard et al., 2017, p.179). We all have a psychological predisposition to relieve the negative emotions caused by the experience of another's distress (Merchant et al., 2010), and this seems to be most true for strategies aimed at acquiring donors.

To summarize, bridging the gap between nonprofits and a long-term relationship with a new donor base can be done by understanding their connection to an organization, and leveraging that to inform solicitations. More is needed to understand how best-practices in relationship building, which includes timely thank yous and communications that bring donors closer to the impact of their contributions, alters donor behaviour. Although, in light of the evidence, implementing these best-practices is likely to improve donor satisfaction and loyalty.

\subsection{Digital Solutions to Address Donor Relationship Best-Practices}

\section{in the Nonprofit Space}

There are excellent examples that illustrate how digital solutions can be used to improve donor relationships.

"Walk with Yeshi" is a chatbot experience created by Charity:Water that allows donors to interact over 
Facebook messenger with the character Yeshi as she walks two-and-a-half hours to find clean water something she does every day (Utley, 2016). Donors receive messages, pictures, videos and hand-written notes from Yeshi that paint a picture of her life, humanizing the issue of water scarcity in Africa (Utley, 2016). Yeshi is a novel example of how machine learning can be used to automate retention processes that save nonprofits time and resources. As well, bringing the beneficiary to life in a chatbot effectively closes the psychological distance between benefactor and beneficiary, allowing donors to better understand the outcomes of their contributions.

An excellent example of how best-practices in transparency and reporting can take shape is in the digital microlending platform Kiva. Lenders using this platform know exactly where, and to whom, their money will be lent. They know how it will be used, the impact it will have on the community, and the history of Kiva loans in the area ("kiva.org", 2019). Since its launch in 2005, Kiva has lent over 1 billion dollars to over 2.5 million people ("kiva.org", 2019). The 1.6 million active lenders on Kiva crowdfund an average of 2.5 million dollars each week to borrowers in over 86 countries around the world ("kiva.org", 2019). Kiva is a great example of how simple reporting and transparent communication is successful in creating a loyal community of donors.

\footnotetext{
“The technologies that allow a company to track individual customers and treat [each of] them differently have made it possible to create what is, in effect, an individual feedback loop for each customer. This loop ensures that a successful relationship continues to get better and better, one customer at a time” (Peppers \& Rogers, 2017, p.76).
}

In regard to implementing greater personalization at-scale, predictive analytics and machine learning algorithms are beefing up customer retention solutions in the for-profit space, helping businesses extract and utilize customer insights out of large data sets (Batra, 2018). A joint study done by MIT and Google of over 370 IT and business leaders revealed that $50 \%$ of businesses planned to use machine learning for greater 
customer insights (Poutonnet, 2017). In fact, this may be part of a larger shift in the industry as predicted by Forrester research, who claims that insight-driven businesses, powered by machine learning, will experience 27\% annual revenue growth from 2015-2020 (McCormick, 2016). A report by MIT Sloan Management Review finds that analytically mature organizations, who derive insights from many data sources, have a marked competitive advantage, and are twice as likely to report strong customer engagement than less mature organizations (Ransbotham \& Kiran, 2018, p.4).

This is not reflected in nonprofit technologies and adoption of machine learning. "Advances in constituent relationship management systems provide fundraisers with better reconnaissance for specific donors" (Manner-McLarty, 2017, p.4). However, according to research conducted in 2019 by Salesforce, a popular donor relationship management platform, only $5 \%$ of the 450 nonprofit leaders surveyed employ machine learning to automate some aspect of their operations (Salesforce, 2019). This is expected to grow by 361\% over the next two years (Salesforce, 2019) as many solutions crop up in predictive analytics, helping nonprofits identify opportunities within current Donor Management Systems for upgrading, cross-selling, or saving current donors.

Maintaining lasting relationships with donors is of the utmost importance, and so employing marketing tools and materials that are "carefully adapted to the donation context" is absolutely necessary (Boenigk et al., 2013, p.545). Tools to automate donor insight extraction for more effective and efficient personalization at scale are less abundant, but slowly appearing. 


\subsection{Learnings from Customer Experience and Insight Strategy in the}

\section{For-Profit Space}

“Cultivating a profitable customer relationship with any one customer will depend primarily on having information about that specific customer and using it wisely; it will matter more than who has the biggest pile of customers” (Peppers \& Rogers, 2017, p. 76). A successful customer experience relies on meaningful personalization, an omni-channel presence to the customer, further strategic learning on customers, and implementation of the latest technology in machine learning, geolocation and customer feedback (Batra, 2018).

These ideas have successfully penetrated the for-profit world (Batra, 2018). Customer-centricity is now a fundamental pillar of all business decisions and activities, and has taken on new meaning in Design Thinking and Agile methodologies that are helping companies put the customer before every business decision (The Conference Board, Inc., 2017). Design Thinking and Agile approaches effectively allow an enterprise to "put themselves in the customer's shoes," and understand what's important to them (The Conference Board, Inc., 2017, p. 2). Data is rewarding enterprises seeking to do exactly this, and extract certain insights for welldefined and clear business objectives (Ransbotham, 2018).

Although B2C and B2B relationships are markedly different than N2D (nonprofit-to-donor) relationships, what is congruous between a profitable consumer and donor relationship is trust. Trust is integral, as an emotional connection to an enterprise does not predict a relationship (Peppers et al., 2017). Trust is a strong indicator of success in all aspects and stages of a relationship. Without trust, there is very little chance that communications and solicitations otherwise will be reviewed favourably, or acknowledged. The more an enterprise demonstrates that it understands its constituents, the more likely it is that this value-exchange and iterative process that defines a profitable, trusting relationship can take place (Peppers et al., 2017). This comes from understanding areas of friction and pain points that allow for continuous improvement, iteration, 
and optimization of the relationship and its interactions (The Conference Board, 2017). Analytics can help identify with greater accuracy and efficiency the sentiment, and areas of friction within customer interactions (The Conference Board, 2017). Of course, in the for-profit world, this is easily accomplished with many automation and analytics services that help an enterprise do exactly this. However, more of these relationshipfocused, insights solutions are needed in the nonprofit world.

The Mailchimp Marketing CRM platform is a good example of a CRM that has expanded their offerings to include better relationship-building and insight features (Mailchimp, 2019). Mailchimp's CRM uses data from existing contact lists and campaigns to offer a more comprehensive, insight-led overview of their client's audiences, including engagement suggestions, lifetime value, look-alike audiences, advanced tagging and segmentation, and automated personalization at scale (Mailchimp, 2019). It allows clients to learn more about their audience demographics and preferences through an audience dashboard feature that visualizes segments based on the aforementioned criteria (Mailchimp, 2019). As well, one-click campaigns created using previous customer behaviour, interactions and buying history, make insights actionable (Mailchimp, 2019). Mailchimp offers a very large and comprehensive list of integrations with other platforms, including those in the nonprofit space, making execution of these insights across a client's technological ecosystem that much simpler (Mailchimp, 2019). Clearly these types of solutions embody best-practices in relationship building and make increasing the lifetime value of customers more efficient and effective.

In addition to analytics, loyalty programs have long been used by for-profit business to secure repeat purchases from their customers. However, as companies continue to want more insights and personalization capabilities these offerings are becoming less about repeat purchases (Collins, 2019). In fact, the latest customer experience intelligence encourages gamification of experiences by rewarding sticky behaviours (The Conference Board, Inc., 2017). According to Forrester Research, "the structure of loyalty programs allow marketers to collect a variety of rich data from customers, including information about their profiles, behaviors, and preferences" (Collins, 2019, p.2). Loyalty programs that are transforming data into more 
insights and providing optimal usability and integrations across the experience ecosystem of a customer are the most competitive in the market today (Collins, 2019). CrowdTwist, as identified in a Forrester Research report this year, is a front-runner in the loyalty market today (Collins, 2019, p.4). CrowdTwist is a software-asa-solution (SaaS) company that uses customer insights to power its' easy-to-use program that provides clients the ability, out-of-the-box, to track and reward hundreds of purchase and non-purchase behaviours like social shares and survey responses (Collins, 2019, p.8). It is clear that modern loyalty programs are expanding their offerings to provide their clients a solid system and platform for building long-term relationships with their customers. This has great potential in the nonprofit world to make long-term donor-nonprofit relationships more likely and should be further explored.

\section{Chapter 3}

\section{Methodology, Implementation \& Evaluation}

\subsection{Methodological Framework}

The Lean Canvas model continues to revolutionize digital entrepreneurship and innovation. Created by Ash Maurya, the Lean Canvas is a highly portable, editable, faster version of the original business model by Alex Osterwalder (Maurya, 2012).

The systematic process described in Running Lean (Maurya, 2012), as well as The Startup Owner's Manual (Blank, 2012) is a practical series of actions in which to test the assumptions behind your original vision and achieve a 
valid lean canvas, or business plan, before running out of resources. In clearly outlined stages, the entrepreneur gets to a business plan more likely to succeed without reaching the proverbial midnight on their available resources. These stages are Problem/Solution Fit, Product/Market Fit, and Scale (Maurya, 2012, p.19), or Customer Discovery, Customer Validation, Customer Creation and Company Building in Blank's model (Blank, 2012).
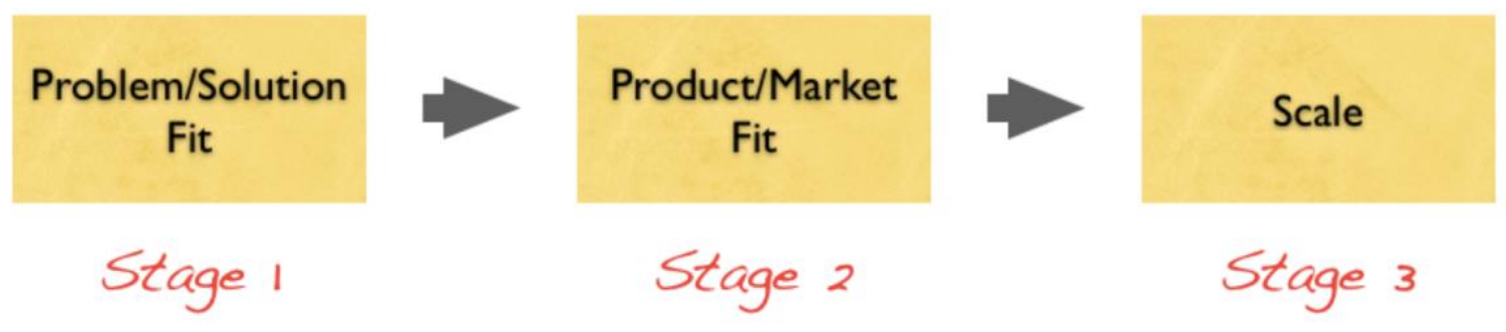

Figure 1. The Three Stages to Startup Success (Maurya, 2012).

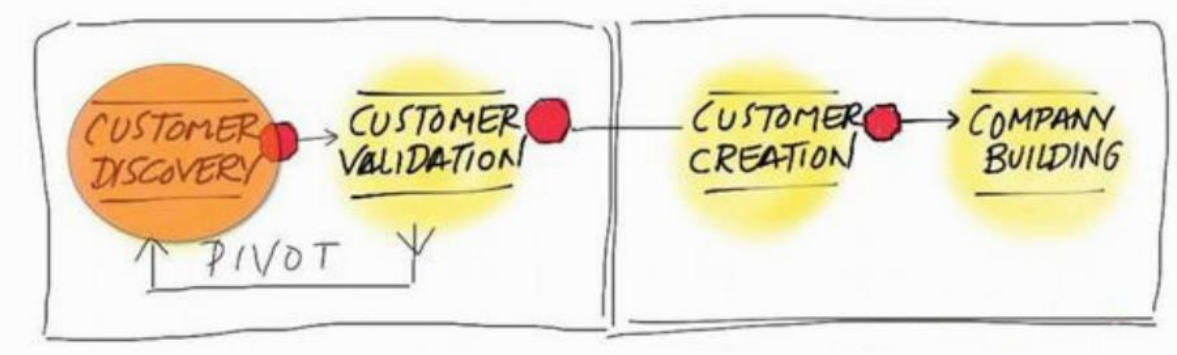

Figure 2. The Four Stages to Building a Successful Startup (Blank, 2012).

For the purposes of this investigation, the focus was on finding Problem/Solution Fit, or Customer Discovery, as per the Lean Startup methodology, and Customer Discovery research techniques, as represented in the above figures. Similar to Design Thinking, Problem/Solution Fit is found by "decoupling the problem from the solution" and interviewing potential customers, in order to find a problem that they have, would pay to solve, and can be addressed through a digital solution (Maurya, 2012, p.19, 36). The process of searching for Problem/Solution Fit is inspired by the Scientific Method and creates a model, or 
Lean business model, in which to house an initial hypotheses of the customer and their problem (Maurya, 2017).

Both Blank (Blank, 2012) and Maurya's methodologies then urge the researcher to interview the potential customer in order to validate, or invalidate, their initial assumptions (Maurya, 2017). The purpose of these interviews is to understand a potential customer's world view and daily context, which generate the empirical evidence that either supports or denies an initial hypotheses (Maurya, 2017). The structure of the interview is designed to explore the past and the present only in order to avoid bias in connection to future speculation and assumption (Maurya, 2017). The 'problem interview' is designed to identify early adopters by their psychographic and behavioral triggers by asking about desired outcomes and the associated negative triggers that push them to pursue such an outcome (Maurya, 2017). In doing so, the researcher understands with more accuracy an early adopter's motivations and level of discomfort with the negative triggers that push them toward a desirable outcome. This also lays the foundation for questions surrounding what participants currently do to pursue said desirable outcome, allowing the researcher to understand what alternative solutions exist, in addition to their challenges and deficiencies (Maurya, 2017). Once the researcher's hypotheses have been validated through empirical, qualitative data the next stage is to test and define a solution by conducting solution interviews (Maurya, 2017).

In this setting, the assumptions or hypotheses to be tested and validated are the research questions under investigation. The first research question expands on this methodology and aims to satisfy an understanding of the greater problem-context surrounding poor retention at nonprofit organizations. Its purpose is to produce a wide and in-depth snapshot of the most common challenges facing the participants and is an important part of the contributions of this paper. All three research questions under investigation outline a road map, or funneled approach to this investigation resulting in a problem worth solving. When facing such a complex social and business problem, seeking the larger picture may be a worthy exercise. 
The following three assumptions underlie the research questions that form the main arguments of this paper:

1) There are common challenges and themes that occur across the sector which can support poor retention trends in the nonprofit industry.

2) Within these common themes or challenges, there are customers who have a problem they are actively solving. In other words, there is a problem worth solving in connection to poor retention.

3) There is a digital solution to this problem worth solving.

The preceding steps outline the process that was followed to test the aforementioned assumptions and arrive at problem-solution fit:

1) Identify potential customers of the problems surrounding poor retention at nonprofit organizations. Recruit voluntary participants that fit the profile of a potential customer.

2) Hypothesize their biggest problems in relation to poor retention at their organizations.

3) Conduct problem interviews. Through the Customer Discovery process, interview voluntary participants, or prospective customers, in a semi-structured style to test the hypothesized problems surrounding poor retention.

4) Understand the greater problem. Analyze and draw broader themes across all interview material to arrive at a snapshot of the greater problem-context of poor retention at participating nonprofit organizations.

5) Understand the problems for potential customers. Narrow the pool of interview data to include only those participants who have a problem related to poor retention, know they have it, and are actively trying to solve it (Maurya, 2012). Analyze and synthesize data to draw themes and hypothesize a problem worth solving.

6) Draft a unique value proposition and build a demo of a solution to the hypothesized problem that delivers on this unique value. 
7) Conduct solution interviews with identified customers. Validate the hypothesized problem through a second round of semi-structured interviews. Verify whether the solution demo contains the minimum necessary features to solve this problem.

8) Is the hypothesized problem worth solving? Synthesize feedback to arrive at conclusive proof or disproof of the hypothesized problem.

9) If feedback gathered during this stage results in a disproof of initial assumptions and hypotheses, a new problem worth solving must be found by digging deeper into the data gathered during the problem interview stage, or widening the pool of data by repeating steps 2-8 (Maurya, 2017).

\subsection{Implementation}

\section{1) Identifying potential customers.}

Criteria to recruit participants was based on professional lived-experiences with building and maintaining relationships with individual donors through digital channels. This narrowed the pool to professionals at nonprofits where growth and sustainability were dependent on monetary

contributions from individual donors. Recruitment criteria also depended on the roles that were most connected to poor retention and were the closest to the problems surrounding poor retention at their organizations (Maurya, 2012, p.74). The goal with the first round of interviews was to "cast a wider net" as this would result in a more accurate cross-section of the problem of poor retention (Maurya, 2012, p.96). The second round of interviews would provide greater opportunity to narrow the pool down to potential customers (Maurya, 2012, p.96).

Given the short time frame of this investigation, distinguishing between a user of a solution to a problem surrounding poor retention and a customer was the main challenge. This distinction can be made by understanding who will use the solution and who will pay for the solution to a problem worth solving, in this case in the greater context of poor retention (Maurya, 2012, p.39). Navigating 
the fluidity of roles at nonprofit organizations and identifying decision-makers with the necessary experience made recruitment difficult. As well, identifying the level of digital maturity at participant's nonprofit organizations, or assessing their relevance under the recruitment criteria, was also a challenge under such a short time frame.

Time also limited the primary researcher geographically, meaning that only participants in Toronto, Ontario were recruited for voluntary participation.

Participants were identified through searches on LinkedIn and nonprofit websites based on an understanding that they fit the aforementioned criteria. They were then recruited through direct message on LinkedIn, email, and some recruited by referral from other participants. They were given consent forms and onboarded accordingly so that their participation was completely voluntary, pertaining to the ethical criteria and requirements preceding the recruitment.

\section{2) Hypothesize their main problems surrounding poor retention at their organizations.}

Through careful research, some of which has been addressed in chapter 2 of this paper, the following were the top hypothesized problems facing potential customers.

1) Nonprofits often don't have or devote the resources necessary to effectively mobilize their databases and channels in order to retain their donors, nor do they devote the time to understand how investment in their existing donor base will result in long-term growth.

2) This perpetuates the understanding that donor retention is resource-heavy, overshadowing the cost-benefit of relying more on existing donor relationships. 


\section{3) Conduct problem interviews. Through a "customer discovery" process, interview voluntary participants, or prospective customers, in a semi-structured style to test the hypothesized problem and explore other areas of possibility.}

The customer interview is a form of "qualitative validation that is quite effective in uncovering strong signals for or against hypotheses using a "reasonably" small sample size” (Maurya, 2012, p.80). This phase of the process allows for an active separation of problem and solution so that the primary researcher may gather the evidence they need to form a hypothesis that supports their original assumptions, or entirely new assumptions, as a result of further exploration into the problem space (Maurya, 2012). The goal with the problem interview is to find potential customers and learn how they currently solve the problems surrounding poor retention, which will be formative to creating a position, pricing structure as well as determining competition (Maurya, 2012, p.100). Similarly, the Customer Discovery process, pursued in combination with Lean Startup methodology, is about validating or invalidating the researcher's assumptions, or hypothesized problem, by "getting out of the building" and talking to potential customers (Blank, 2012, p.192). Going through this process of validating an initial vision ensures that the primary researcher has properly defined and identified a problem that many customers want solved in order to bolster long-term success (Blank, 2012, p.195). In other words, this phase of the Customer Discovery process helps the researcher understand whether the problem they've identified is "big enough", and "important enough" to pursue (Blank, 2012, p.220).

These interviews were conducted in person as this provides the richest data including non-verbal clues to the researcher, and are more open-ended, and less biased than surveys and focus groups (Maurya, 2012, p.80). They allowed the researcher to delve into areas of understanding not previously explored, and achieve a more nuanced picture of the problem-context. In other words, they provided the most reliable learning on who potential customers are, what their greatest pains are, and how they 
would address these problems today (Maurya, 2012, p.104). These are the desirable outcomes of the problem interview process.

A Customer Discovery interview script was created in order to facilitate semi-structured interviews with voluntary participants, or potential customers. The script was created using the Lean methodological framework, which has been validated repeatedly and on a wide scale by digital entrepreneurs as a means to test their assumptions (Maurya, 2012). It is continually updated and improved by the author, in light of new evidence, so that it maintains its relevance in a mutable digital landscape (Maurya, 2017).

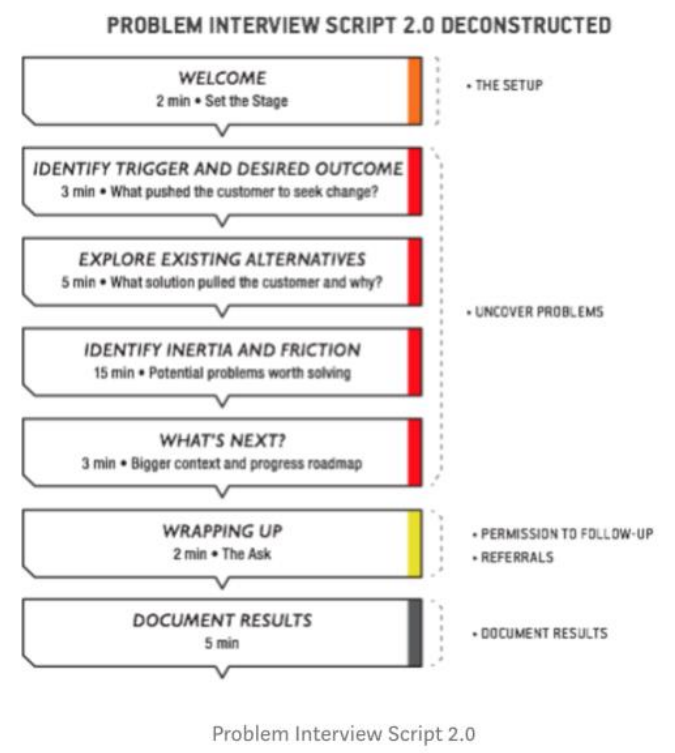

Fig 3. Problem Interview Script Structure 2.0 (Maurya, 2017).

Interviews were conducted by the primary researcher in a private room when possible to ensure privacy and confidentiality. Notes were taken during the interview and recorded for future analysis. On average, interviews lasted around 45-55 minutes including time to go over the consent process, ensure confidentiality, a briefing, and debriefing. 
Interview recordings and notes were reviewed weekly to ensure progress towards finding early adopters in the recruitment process and refining the interview script to better test the hypotheses, as was recommended under the lean methodological framework employed (Maurya, 2012).

\section{4) Understand the greater problem. Analyze and draw broader themes across all interview material to arrive at a snapshot of the greater problem-context of poor retention at nonprofit organizations.}

The Affinity Diagram is a project management tool, or brainstorming technique, that organizes large, disorganized data sets from different sources such as ideas, opinions, and other information, into groupings based on natural relationships (Kiran, 2017, p.291-311). It provides a visual map, or representation, of related data from large data sets, and is often used when confronted with complex, seemingly chaotic problems (Kiran, 2017, p.291-311). The process of creating an Affinity Diagram begins with an Affinity Sort, where the researcher writes down short phrases or sentences representative of data items on a post-it note, clustering similar items together (Kiran, 2017, p.291311). Each grouping of similar items is then given a short 'header card' describing the grouping in 3-5 words, and relationships between groupings are considered (Kiran, 2017, p.291-311). Sorting, however, should not begin until after each idea is properly represented and clear, and the need for more ideas from participants has been considered (Kiran, 2017, p.291-311). 


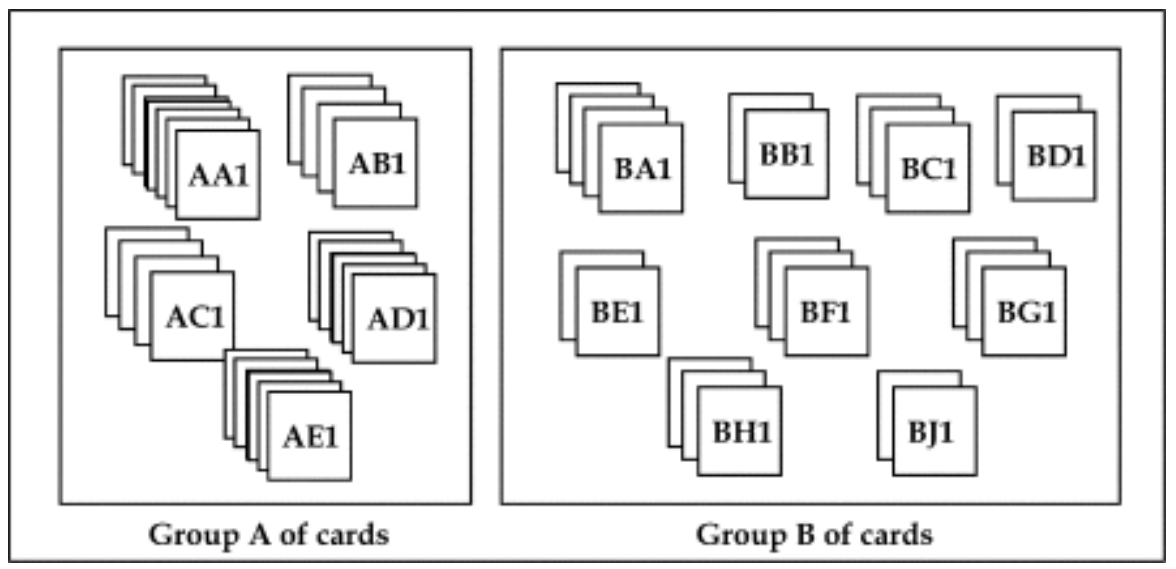

Fig 4. Illustration of card arrangement for Affinity Diagram (Kiran, 2017, p.291-311).

This process was used to create an Affinity Diagram from the interview data, visualize and draw broader themes. Using the program Miro, insights were drafted on digital post-it notes by listening to each interview in depth and reviewing interview notes and partial transcripts. The affinity process began by placing an insight on a digital post-it. The second insight was placed near the first if they were similar enough, otherwise it was placed in a different location, or grouping. This was done until all insights were accounted for and all clustering of insights were comprised of related insights. Once these clusters were properly vetted, they were labeled with a theme, and related themes clustered together to form larger themes.

After following this method, interview insights from all participants were clustered together to form themes surrounding poor retention at nonprofit organizations. These themes were then synthesized into the larger foundational themes that underlay many of the other problems surrounding poor retention. Thus, the problem context of poor retention at participant nonprofit organizations was understood, and the first research question addressed. The findings of this will be discussed in section 3.3. 
5) Understand the problems for potential customers. Narrow the pool of interview data to include only those participants who have a problem related to poor retention, know they have it, and are actively trying to solve it (Maurya, 2012). Analyze and synthesize data to draw themes and hypothesize a problem worth solving.

The problem interview exit criteria is as follows: know the demographics of an early adopter and know their biggest problems and how they currently solve them (Maurya, 2012, p.121). The exercise of analyzing all participant data made it easier to generate the exit criteria of the problem interview and narrow down the data pool to early adopters, or potential customers. Once potential customers were identified, the same affinity diagramming method was employed to arrive at themes comprised of related insights surrounding poor retention found through the problem discovery process. Clustering of these insights was done with the intention of arriving at potential problems worth solving, or a problem hypothesis, for the customer pool under analysis. This resulted in a hypothetical problem worth solving.

The results of this satisfy the second research question and will be discussed in the following evaluation section 3.3 of the paper.

6) Draft a unique value proposition and build a demo of a solution to the hypothesized problem that delivers on the unique value proposition.

A unique value proposition (UVP) is a succinct description of how your solution will deliver exponential value to the customer that is unparalleled and comprises the competitive advantage (Maurya, 2012, p.46). It is a declaration of the desired outcome you believe will deliver exponential value to the problem a customer is currently trying to solve. 
Focusing on the hypothesized problem worth solving for the potential customer pool, a unique value proposition was crafted which informed the solution to be sought as the answer to the problem.

Following that was a list of how potential customers to this problem currently solve it today (Maurya, 2012, p.51). A competitive audit was done of digital solutions, both in the nonprofit and for-profit space, offering similar value. This allowed the primary researcher to fortify the main features of a potential solution that might deliver unique value in this space. These solutions were not fully defined but were conceptualized enough to deliver on the value outlined in the UVP.

The next step was to create a demo of the solution in order "to illustrate visually how [the solution might] intend to solve the problem, [and] convey [the] unique value proposition" (Maurya, 2012, p.125). The solution demo was created in the form of a 3-minute video outlining how it would deliver unique, exponential value to the hypothesized problem worth solving. This involved the creation, by the primary researcher, of a video script as well as video art, and animations. The demo video enveloped the hypothesized problem, the unique value proposition, and main features of a solution to deliver on the unique value proposed. This allowed the primary researcher the ability to test and validate the hypothesized problem worth solving, and the solution to solve it.

\section{7) Conduct validation interviews with identified customers. Validate the hypothesized problem through a second round of semi-structured interviews. Verify whether the hypothesized problem is worth solving, and whether the demo contains the necessary features to solve this problem.}

Interviews with identified potential customers of the hypothesized problem worth solving were scheduled. Given time constraints, only those interviewed in the first round were contacted, although it is advisable to recruit new participants, or early adopters, at this stage (Maurya, 2012, p.133). During this phase of the Customer Discovery process the main goals are to verify whether the 
researcher has properly understood the needs of early adopters, and their problems, and has created a minimum viable demonstration of the solution to solve the problem (Blank, 2012, p.221). As well, this phase also provides evidence in which to validate or invalidate the unique value proposition created in the previous step (Blank, 2012, p.222). The steps of this process are illustrated below and comprise some of the processes that have been followed in previous steps to arrive at this, penultimate step.

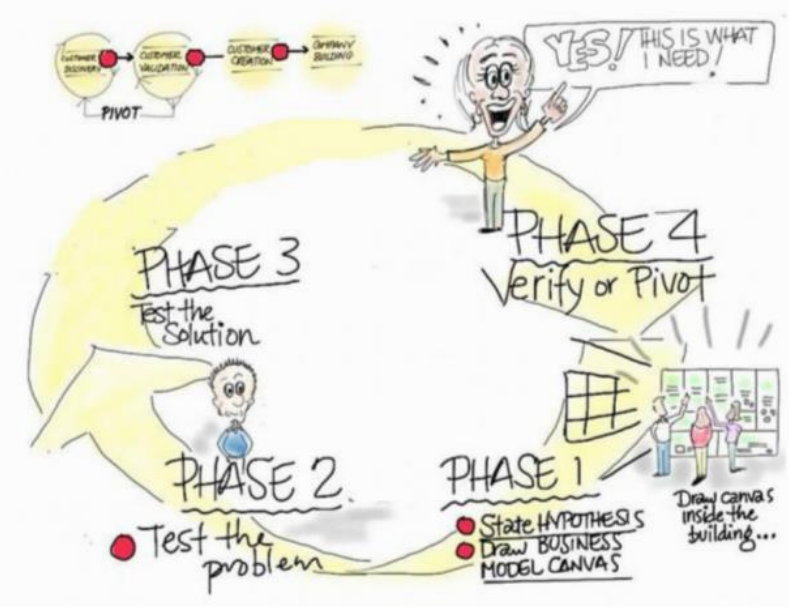

Fig. 5 The 4 phases of customer discovery (Blank, 2012, p.219).

An interview script was created to validate or invalidate the hypothesized problem worth solving and gather feedback on the solution demo as well as pricing structure. The script was created under the Lean methodology, informed by the interview structure pictured below. 
SOLUTION INTERVIEW SCRIPT DECONSTRUCTED

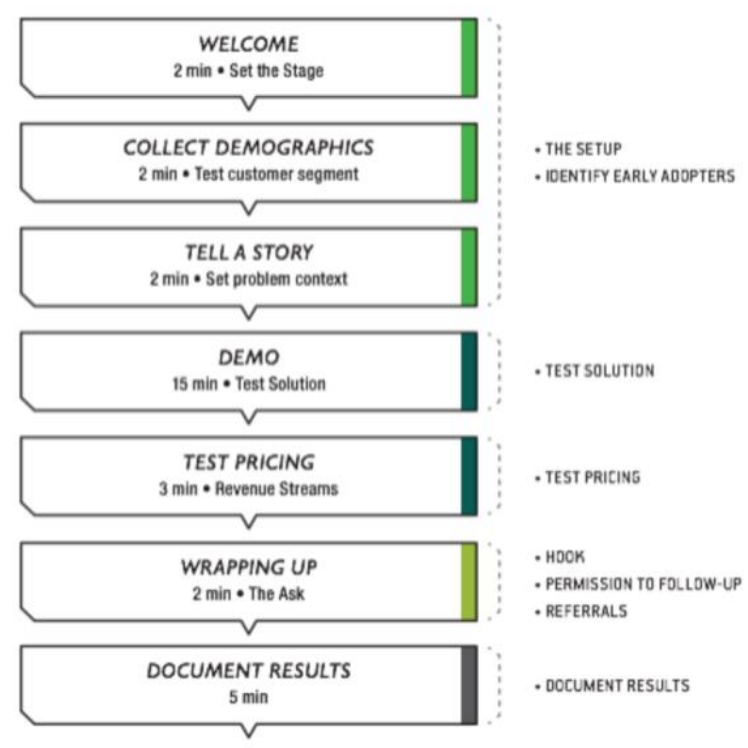

Fig 6. The Solution Interview Script (Maurya, 2017).

6 potential customers were interviewed, adhering to optimal numbers of participants for the purpose of testing a solution and gathering feedback, according to research (Nielsen, 2000).

During these interviews, the hypothesized problem worth solving was presented back to the participants in the form of interview questions and demo video. Their responses were recorded, and notes taken by the primary researcher for further analysis later. Similar to the first phase of interviewing, the semi-structured interviews lasted around 40-50 minutes each. The role of the researcher during this interview was to understand participant's reactions and feedback to the material in as much depth as possible, so as to get an accurate understanding of whether Problem/Solution Fit was achieved or not, thereby answering the second research question.

\section{8) Is the hypothesized problem worth solving? Synthesize feedback to arrive at conclusive} proof or disproof of the hypothesized problem. 
Similar to step 5, recordings and notes of solution validation interviews were listened to and analyzed using an Affinity Diagram where answers to open-ended questions were clustered together to form themes. Feedback helped to hone in on the main value of the proposed solution and highlight barriers to paid adoption in the nonprofit space. The hypothesized problem worth solving was validated as a problem facing the customer participants. As well, the UVP was validated in addition to 2 out of 3 of the solution features included in the demo.

Problem/Solution Fit is found when the researcher may accurately identify early adopters, their 'must-have' problem, a defined set of minimally viable features needed to solve this 'must-have' problem, and a viable price the customer is willing to pay for these features (Maurya, 2012, p.144). Alternatively, the Customer Discovery phase has concluded when the researcher has validated their understanding of the customer and their problem, the UVP as a concise verbalization of the solution to that problem, and has verified that enough customers have this problem, and are willing to pay a price for it that would support a business long-term (Blank, 2012, p.222).

\subsection{Evaluation}

The following section will discuss the results of the process and methods described in the previous sections of this chapter as it pertains to each of the research questions under investigation. A detailed, step-by-step description of the primary data analysis and synthesis for each of the following research questions can be found in Appendix A.

\section{Research Question 1: Given the cost-benefits of improving retention, what are the most common reasons that prevent nonprofits from relying more on their current donor base for funding?}

The answer to this question was reached by following steps 1-4 outlined in detail in section 3.2. 
27 participants that were recruited volunteered to participate and be interviewed in person. They all had professional lived-experience with building and maintaining relationships with individual donors through digital channels. They occupied roles in direct marketing, stewardship and recognition, or development in a digital capacity with the majority responsible for executive and/or managerial direction in these roles at their nonprofit, or at nonprofit consultancies.

These 27 participants represented 19 nonprofit organizations and 4 consultancies. These 19 nonprofit organizations were from the following areas of service:

1) Mental health

2) Addiction Services

3) Social Services

4) National and International Disaster Relief

5) National and International Humanitarian Aid

6) Environmental Protection

7) Health Care

8) Community Arts

9) Wildlife protection

10) Religiously-Affiliated Organizations

11) Higher Education

12) Sector Digital Consultants in:

- Lead Generation

- Digital Fundraising and Advertising

- Stewardship 
$11 \%$ of participants were from very large nonprofit organizations with a gross annual revenue of approximately 250 - 750 million dollars in 2018. 15\% of participants were from large nonprofit organizations with a gross annual revenue of approximately 25 - 150 million dollars in 2018. 7\% of participants were from advocacy organizations with a gross annual revenue of 2.5 - 4 million dollars in $2018.37 \%$ of participants were from mid-sized nonprofit organizations with a gross annual revenue of approximately 5 - 12 million dollars in $2018.19 \%$ of participants were from consultancies that supported lead generation, marketing, fundraising and stewardship efforts through digital.

The following assumption underlying the first research question — there are common challenges and themes that occur across the sector which can support poor retention trends in the nonprofit industry — was validated after gathering, analyzing and synthesizing the data from all participants. The full scope of problem themes surrounding poor retention, and relationships identified between them, is illustrated in the figure below. Two large problem themes visualized as larger headings formed the root of many other problem themes, and were consequences of these main themes. The problem theme Difficulty Designing Successful Donor Journeys/Experiences, however, being the exception. This theme is shown as a direct result of the other main theme, and its sub-themes. 


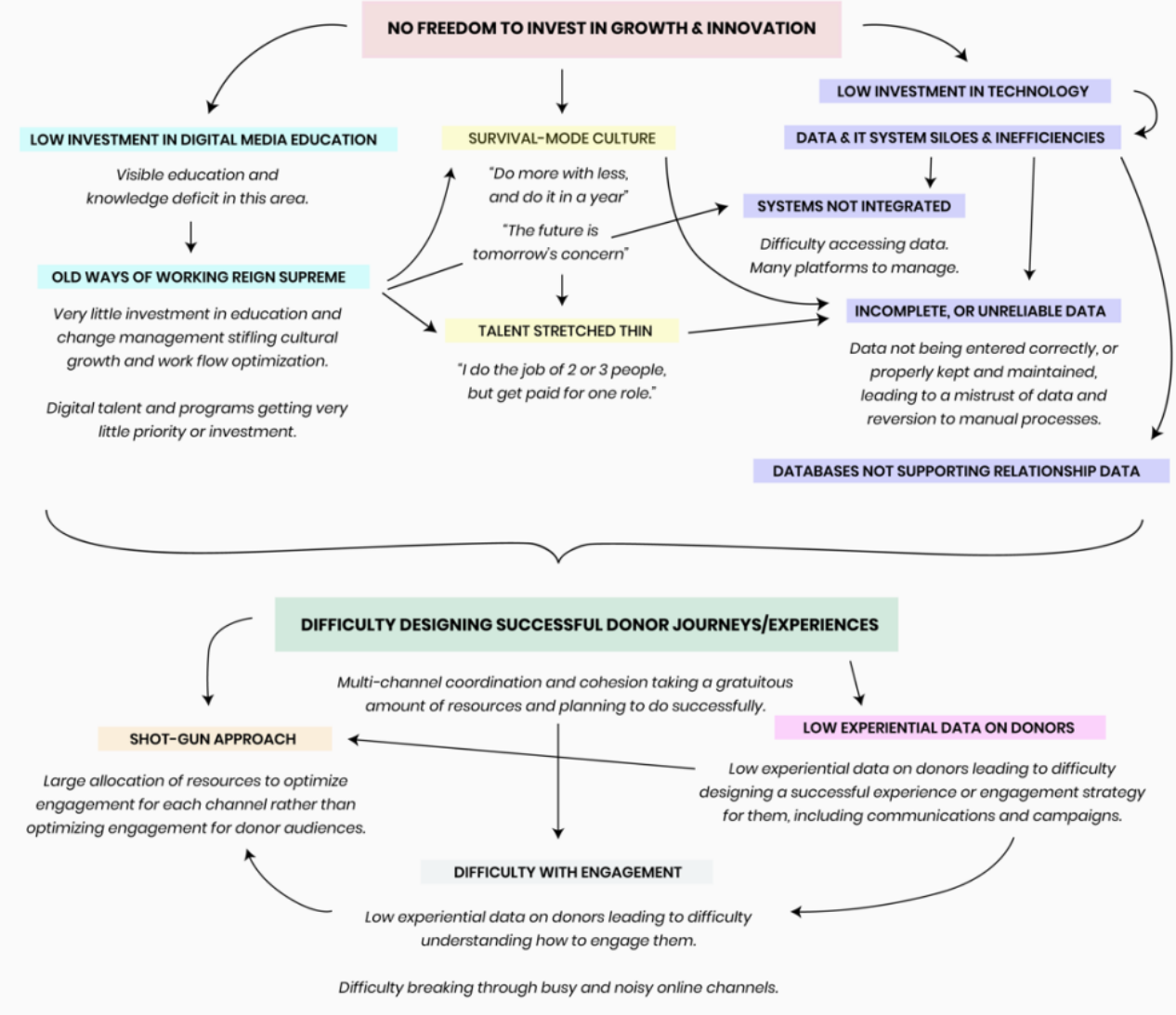

Fig 7. Problem themes surrounding poor retention at participating nonprofits and nonprofit consultancies.

One of the two following hypotheses created before data collection were supported by the findings as a result of data analysis and synthesis, they were:

1) Nonprofits often don't have or devote the resources necessary to effectively mobilize their databases and channels in order to retain their donors, nor do they devote the time to understand how investment in their existing donor base will result in long-term growth.

This was unsupported by the data as it lacked an understanding of the greater problem-context. The resource deficit was a result of pressure to keep operating costs low, which supported a survival-mode culture, lack of foresight, and overburdened talent. This also caused low investment in longer-term goals such as improving retention and lifetime giving value of donors. 
2) This perpetuates the understanding that donor retention is resource-heavy, overshadowing the costbenefit of relying more on existing donor relationships.

This was partially supported by the data. The problem themes surrounding poor retention could be seen as inflating the costs of focusing on existing donors. All of the problem themes surrounding poor retention make implementing best-practices difficult. However, based on the data findings it could be concluded that the theme of 'survival-mode culture', in particular, makes investing in relationships past a year culturally and fiscally inaccessible and difficult, especially when talent and performance measures are limited to a 12-month time period. This notion was expressed by almost every participant, who were measured based on how much money they were bringing in within the year.

A detailed overview and account of the data, as well as the analysis and synthesis process, can be read in Appendix A.

\section{Research Question 2: Of the most common problems that prevent nonprofits from improving their retention, which are they actively trying to solve?}

The following assumption underlying the second research question was supported by the data:

Within these common themes or challenges, there are customers who have a problem they are actively solving. In other words, there is a problem worth solving in connection to poor retention.

Early adopters, characterized as having a problem surrounding poor retention they are aware of and actively solving (Blank, 2012, p.202-3), were identified as having the following characteristics:

1) They were working at very large and large organizations, advocacy organizations, or consultancies. 
2) They were responsible for stewardship, direct marketing or development in a management or executive position.

3) Their organizations were actively creating, implementing, or optimizing a donor journey or experience online.

4) They weren't experiencing as many of the problem themes related to poor retention, and had bigger budgets, more educated talent, and a more progressive, modern culture.

After proper analysis and synthesis of early adopter data, the problem early adopters were aware of, actively solving, and could be addressed through a digital solution was 'challenges getting and using donor insights'. By not experiencing as many structural problems surrounding poor retention, early adopters had an advanced understanding and ability to create and strategize donor experiences, but were facing challenges in doing so effectively and efficiently. This problem was verified during the solution validation phase by $100 \%$ of the early adopters interviewed. The below figures highlight the problem area that early adopters were actively solving for. 


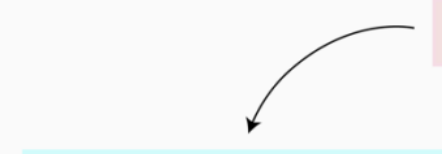

LOW INVESTMENT IN DIGITAL MEDIA EDUCATION

Visible education and

knowledge deficit in this area.$$
\downarrow
$$

OLD WAYS OF WORKING REIGN SUPREME

Very little investment in education and change management stifling cultural growth and work flow optimization.

Digital talent and programs getting very little priority or investment.

\section{NO FREEDOM TO INVEST IN GROWTH \& INNOVATION}

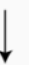

SURVIVAL-MODE CULTURE

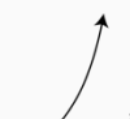

"Do more with less, and do it in a year"

"The future is tomorrow's concern" $\downarrow$

TALENT STRETCHED THIN "I do the job of 2 or 3 people, but get paid for one role."

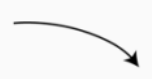

LOW INVESTMENT IN TECHNOLOGY DATA \& IT SYSTEM SILOES \& INEFFICIENCIES

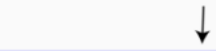

SYSTEMS NOT INTEGRATED

Difficulty accessing data. Many platforms to manage. INCOMPLETE, OR UNRELIABLE DATA

Data not being entered correctly, or properly kept and maintained, leading to a mistrust of data and reversion to manual processes.

DATABASES NOT SUPPORTING RELATIONSHIP DATA

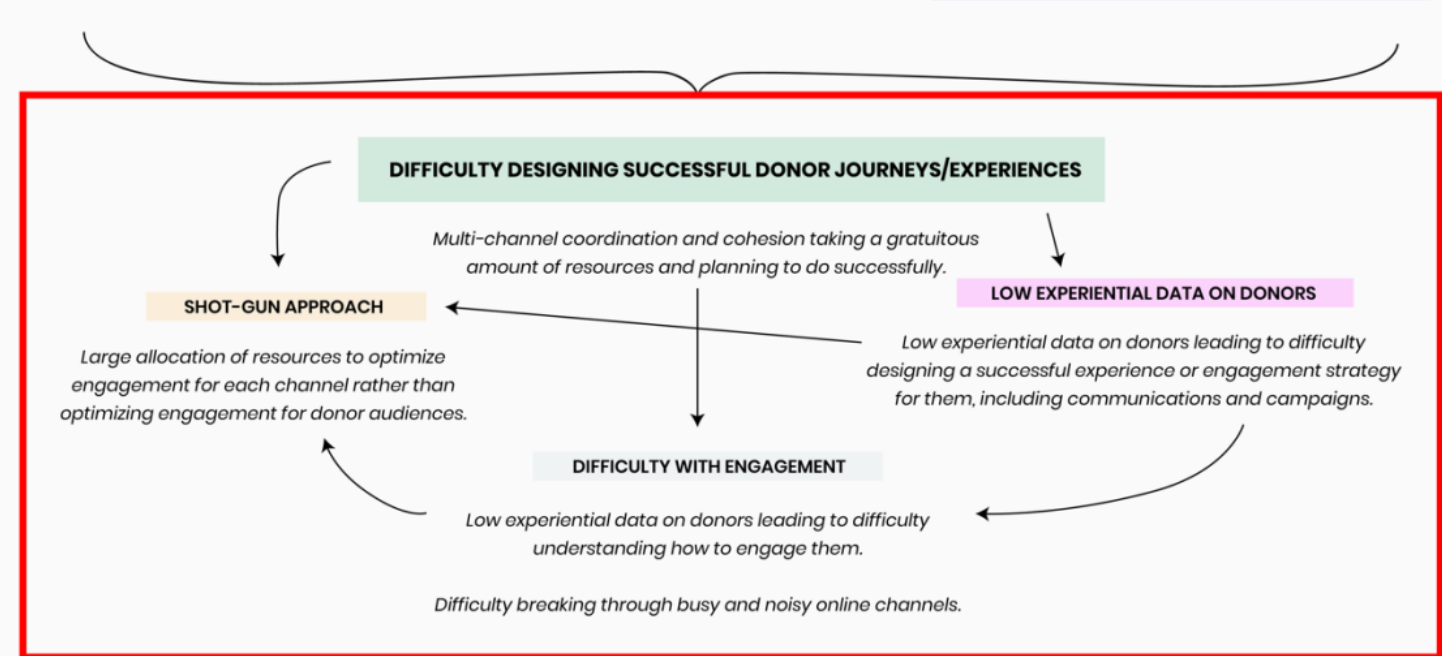

Fig 8 . Early adopter problems within the greater problem-context surrounding poor retention. 


\section{CHALLENGES WITH GETTING AND USING DONOR INSIGHTS.}

DONORS DON'T RESPOND TO SURVEYS
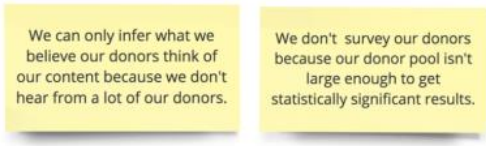

because our donor pool isn't

stistically significant results.

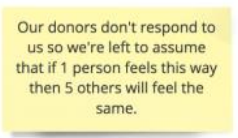

QUANTITATIVE DATA \& METRICS

DON'T OFFER THE FULL PICTURE

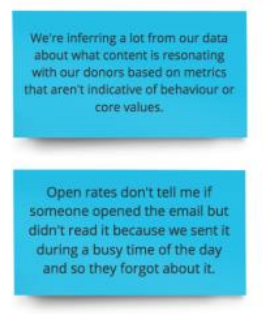

RESOURCE-HEAVY ANALYTICS AND TESTING
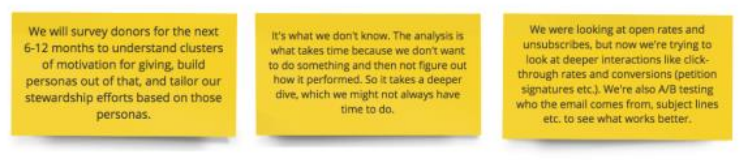

SHOT-GUN APPROACH TO COMMUNICATING

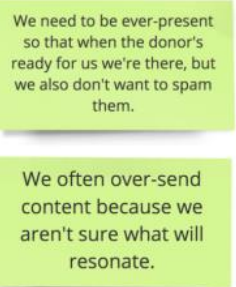
With current donors we just
hope that their awareness of us
is high enough that it leaves em more open and receptive to our communications.

We struggle with awareness of what we do, and why we need the help of donors to do it.

Fig 9. A more concise early adopter affinity diagram.

A detailed overview and account of the data, as well as the analysis and synthesis process, can be read in Appendix A.

\section{Research Question 3: How can a digital solution help them actively solve common problems surrounding poor retention?}

This was answered by completing steps 6-8 outlined in section 3.2, where the UVP, and 2 of the three minimum viable features of a solution to the problem of 'getting and using donor insights' were found to be viable, with one being partially viable. Viability was determined when 6 out of 6 early adopters said they would pay for or use these features after viewing the video demonstration. They also agreed that these features supported the main value proposition, or UVP, underlying the solution features. After gathering, analyzing, and synthesizing feedback from early adopter participants, the following features were validated as having enough value to address their problem worth solving: getting and using donor insights. 
The features were as follows:

1) Automated donor profiles that are 'live', or updating at the discretion of the user, and offer more insights by making powerful inferences on a combination of existing and publicly available donor data.

These profiles provide a more detailed, insightful understanding of a single donor, or cluster of similar donors, and their connection to an organization. They deliver on the main value identified by early adopters as providing more insight on a donor's connection to their organization. These insights provide invaluable direction and intelligence on how to create successful communications when very little insight is available. They also make identifying potential areas of engagement, as well as pain points and friction, possible and worthwhile. As well, these profiles will be updated at the discretion of the user, creating relevant insights and a timeline of relationship and insight data for the organization. This, in combination with quantitative engagement metrics, will provide a powerful source of evidence-based practice in long-term donor relationship building in the nonprofit sector.

"Quantitative and qualitative data of this sort provides the intelligence regarding donor values and preferences required for evidence-based practice, and advances in this area will likely continue as new technologies are developed, new methods for data gathering are devised and more institutions invest in this type of data management" (Manner-McLarty, 2017, p.4).

These profiles also capture level of engagement and advocacy within an existing donor base, helping nonprofits identify high-potential opportunities that may have otherwise been missed. By providing an organization with an accurate, insightful bank of knowledge on their highly engaged, high-value donors recruiting similar quality donors is simpler, more efficient, and more effective. This process slowly builds expertise in both stewardship and acquisition engagement tactics and strategy, improving the economics of both. 
As well, depending on the business objectives and priorities of the organization, the nonprofit may choose to gather insights for a certain group of donors, or choose to have a certain group of donor profiles updated more frequently. For example, the nonprofit may only want to have their major giver profiles "live", and their mid-level donor profiles updated once a month.

2) Insight tags that can be integrated with existing nonprofit databases and donor profiles for more meaningful targeting and segmentation.

The insights that formulate each donor profile, or groups of related profiles, would take the form of insight tags that could easily integrate with existing, popular nonprofit platforms and donor databases. This makes the insights generated in each profile truly actionable. By tagging existing donor lists with insights, profile types, level of engagement, advocacy etc., fundraising and stewardship professionals can easily segment and target communications using these insights and insight profiles. These insights would allow nonprofits to create and send communications to a group of donors that can speak to their connection with the organization, repair an area of friction or complaint, and reach them where they are most active with content that is insightful and personally relevant, and much more.

The following feature was only partially supported by the data:

3) Mobile, insight notifications and one-click stewardship messages that are generated based on the profile of a single donor, or group of similar donors, and relationship-building best-practices.

Mobile, one-click milestone stewardship messages and insight updates make staying on top of relationship best-practices easier and less cumbersome for fundraising and stewardship professionals.

A digital solution which has at least the first two of these three features is a viable solution to the problem worth solving — getting and using donor insights. 
A detailed overview and account of the data, as well as the analysis and synthesis process, can be read in Appendix A.

\section{Chapter 4}

\section{Conclusions, Limitations \& Future Work}

\subsection{Increasing Capacity to Invest in Growth is the Most Urgent}

\section{Take-Away for Nonprofits}

Little to no opportunity for growth and innovation investment was by far the most common, and emotionally charged commentary and data gathered through this investigation. It was the root cause of all other challenges and barriers preventing smarter, more efficient operations, including better donor retention at nonprofit organizations. Misperceptions of efficiency and effectiveness should be challenged, and transparency and reporting rethought in order to grow sustainably and responsibly. Continuing to abide by the misguided beliefs of the public was the root cause of most other problems and inefficiencies and is therefore believed to be the largest problem facing the nonprofit sector.

Efficiency is achieved by thoughtful retrospection, informed strategy and an understanding of the problems to be faced, not only with program work, but with fundraising, stewardship, and all other roles and operations. When systems are siloed, often are people and teams. Without thoughtful coordination there is no hope in achieving the efficiency lauded by potential donors and stakeholders, nor is there meaningful, thoughtful evaluation and reporting. This is key to rebuilding the trust that has eroded between nonprofits and Canadian donors outside the current, shrinking donor base. Younger donors are more concerned with impact over operating costs, and causes over nonprofit brands. 
Donors as well as fundraising and stewardship professionals should be evaluated on their value over a lifetime, not their value within a year. This puts an 'expiration date' on talent and donors and reinforces the 'survival-mode' culture that many participants had, or were experiencing. This 'survival-mode' culture perpetuates inefficient, and sometimes unsustainable operations, systems, and technology that is much more likely to produce waste, unnoticed by those unable to look beyond the tasks of the day or week. As well, when talent is trying to make the year, or meet their daily requirements without too much friction, very little is sacrificed for long-term gain. This may explain the unclean and unreliable information logged on donor management databases, and lack of strategic direction that many participants struggled greatly with. This has a ripple effect on all other data-led activities and digital efforts which rely on strategic direction and retrospection to be effective and worthwhile.

Long-term, profitable relationships should be the currency sought, yet they require a level of thoughtful, strategic intent and action based on reliable knowledge acquired through integrated systems and digitally educated teams that are well-coordinated. Coordination, and an omni-approach to operations also means less resources are required to create frictionless donor experiences and build more long-term relationships with existing donors.

Improving retention would mean investing in growth and innovation. Those that do see the results.

"We've seen higher upgrade rates and higher event attendance since implementing an intentional stewardship plan and process.”

"Since setting up a more deliberate stewardship journey, retention rates have gone up 7\% every year — that's 5000 saved donors and an exponential growth of 250k per year." 
Those in a position to challenge cultural misperceptions of an efficient charity and are, or are able to, embody a different approach to operations and effective evaluation of the nonprofit organizations they belong to are in a powerful position. Those with the capacity to challenge misguided perceptions of how an effective nonprofit should run are advised to take every opportunity to do so, no matter how small. Sharing these experiences with the rest of the sector would make these voices louder. The results of this investigation make it clear that this is the most important conversation for the sector and needs as much attention as it can possibly get.

\subsection{Limitations}

There were limitations which are important to point out and should be considered for future work and learning. Time constraints limited the number of participants for the first round of problem interviews, and significantly limited the number of participants for the second round of solution interviews. With more time the researcher would have been able to attain a representation of the problem of poor retention at an industry level that included smaller nonprofits with a gross annual revenue below 2.5 million. As such, the data pool was limited to participants at very large to mid-sized nonprofits.

Additionally, there was only one researcher, which may have contributed to a limited or biased analysis and interpretation of qualitative data. Although measures were taken, and the research supervisor assisted with this limitation, having multiple researchers may have produced more reliable interpretations and should be considered for future learning. 


\subsection{Future Work}

"Once you have preliminary validation on your hypotheses, you can then use what you have learned to craft a survey and verify your findings quantitatively. The goal is no longer learning but demonstrating scalability (or statistical significance) of the results" (Maurya, 2012, p.80). This would be the next step in fulfilling Problem/Solution Fit and progressing toward Product/Market Fit and Customer Validation under the methodological frameworks used to structure this investigation. Achieving Product/Market Fit, or Customer Validation (Blank, 2012) would mean the entrepreneur has achieved a product that customers want and will pay for (Maurya, 2012).

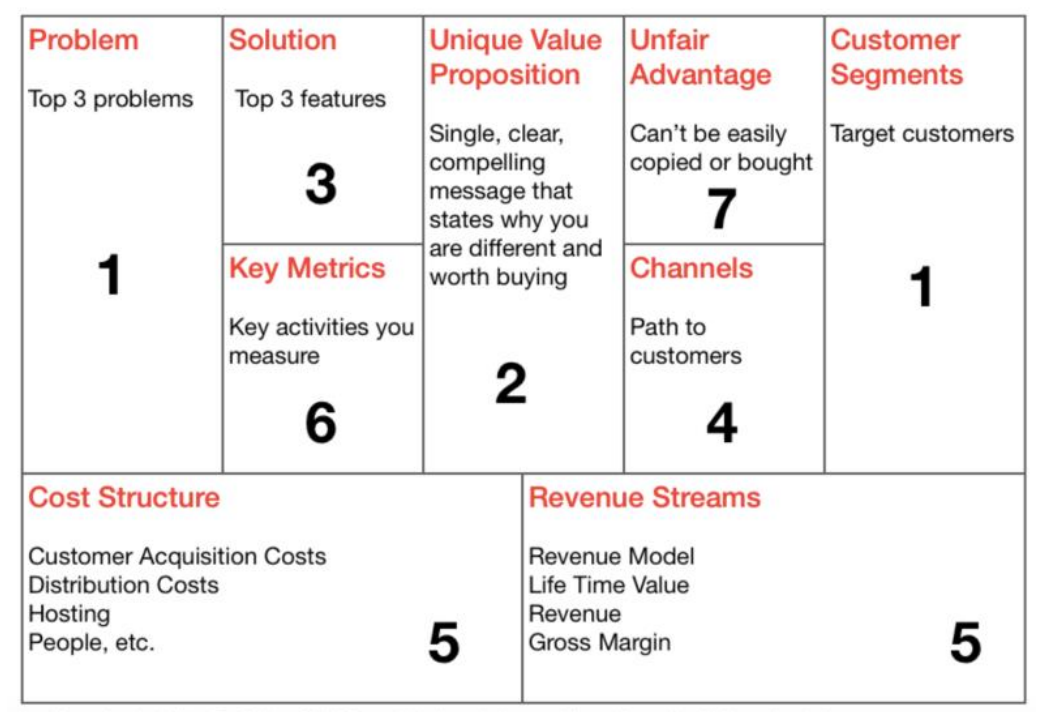

Figure 10. Lean canvas described (p.42, Maurya, 2012).

The above figure depicts and describes the sections of the Lean Canvas. Sections 1,2 and 3 have been explored and fulfilled, leaving sections 4,5,6, and 7. With not everyone agreeing to price, further exploration needs to be done to test pricing structures and revenue streams (5), as well as answering concerns on what investment in resources this solution would require in addition to price. Channels in which to find more early adopters also need to be identified (4), as well as key metrics (6) and the solution's unfair advantage (7), the last thing to be conceptualized before Product/Market Fit can be sought. 


\subsection{Incorporating Feedback and Competing With a Solution to the Problem Worth Solving}

Many early adopters mentioned concerns with data privacy and protection of their donors. Keeping the solution client-server-side would help mitigate these concerns as the data would only exist on the client side, not with the provider or a cloud server.

\section{Potential Pricing Structure}

With mixed reviews on the pricing, and support for the tiered model, a cost-per-constituent approach might be an effective pricing structure for this sector. This would mean a low barrier-to-entry and structure that permits scalable commitment from the nonprofit client. This structure would also allow for different donor groups to be used with the solution in line with variable business objectives. It would provide opportunity to customize features for certain donor groups. For example, if a nonprofit wanted to prioritize better insights on their major givers they could opt into self-updating profiles for this donor group, and layer on smart prospecting to engage more donors at this level. For lower-mid level donors they could opt into profiles that generated new insights every month, and turn off smart prospecting if this wasn't a priority, saving them the higher cost-per-constituent at this level.

Unfair Advantage - Competing With an Innovative Loyalty Program

There were comments made by early adopters on various solutions cropping up in the nonprofit sector that offer similar features. In order to compete there may need to be a more innovative and creative wrapper, or unfair advantage, in addition to the three pillared features mentioned in section 3.3. 
A loyalty program that rewards donors with points for existing engagement and interaction behaviours was shown to be a novel addition to the problem space as identified by $100 \%$ of early adopters. This loyalty program would allow donors to trade in their earned engagement points for matching donations from corporate and government sponsors, or even major givers, thereby amplifying the donor's impact. This would be a unique and novel feature in this problem space. This program would incentivize engagement and provide nonprofits with a completely new system in which to further engage and learn about a donor group of interest while quantifying engagement and tapping into a new stream of revenue. This loyalty program would offer all of the latest technology and features of the most competitive loyalty programs in the for-profit space. Nonprofits could customize the gamification and point structure for interactions based on their business and engagement objectives and create a completely new platform and system for effective and popular donation matching initiatives.

Having this loyalty system as the donor-facing side of an insight-led solution may provide an edge, or unfair advantage, in this competitive problem space as no other similar solutions offer this as a feature.

\section{Integrating a Mobile Giving App}

Evidence gathered outside the parameters of this investigation led to a prototype of a mobile giving app that incorporates all aspects of relationship-building best-practices into one experience for donors. This app augments common social media functions and features to serve these best-practices and provides a better giving experience for younger donors. Donors can view content updates and goal progress on the nonprofit causes they've supported, see their giving history and impact over time, discover the information they need on nonprofits they support, or are thinking of supporting, and discover new causes based on their previous giving behaviour. When a donor gives through the app they will receive a customized thank you and 
information on how their money might be used. Donors can also reach out directly to those working behind the scenes at partnered nonprofits and receive direct messages through the app.

Integrating this app into the solution discovered through this investigation may be another unfair competitive advantage in this problem space as no other donor insight solution has an innovative donor-facing app as part of their offering.

\subsection{Increasing Social, Digital Innovation in the Sector}

Using the methodology applied to this investigation is a viable way to approach this greater problem, and hopefully provides a well-defined journey to Problem/Solution Fit in this sector that others may follow. There are perhaps many other potential problems worth solving, and this investigation may provide social entrepreneurs with an advantage and starting point at which to explore other areas in need of innovation within Canada's nonprofit sector.

\section{Appendix A}

\section{Primary Data Analysis and Synthesis}

Research Question 1: Given the cost-benefits of improving retention, what are the most common reasons that prevent nonprofits from relying more on their current donor base for funding? 


\section{Analysis}

Interviews from all 27 participants were listened to twice, and partial transcripts created in order to analyze the qualitative data and extract insights to be used as part of the affinity diagramming process outlined in step 4, section 3.2 of this chapter. Insights should be characterized here as concise statements from the participant's point of view, which accurately characterize their lived experiences with inefficiencies, challenges, and current solutions to address poor retention at their organizations. These insights were extracted by carefully listening to interview recordings and reviewing notes of the interview experience with that participant.

\section{Synthesis into broader themes}

The following is an in-depth description of the results of the affinity diagramming process.

\section{Major theme: 'No Freedom to Invest in Growth and Innovation'}

This is perhaps the largest and most concerning of the themes discovered through this process. Pressure to keep operating costs low at nonprofit organizations is, according to related clusters of themes, the underlying cause of all subsequent problems surrounding poor retention at nonprofit organizations. With little to no freedom to reinvest in people, technology, or innovation, growth was often described as stagnant and slow, digital and technical system competencies unsophisticated, educational deficits significant, and 'survival mode' persisting, where future growth was often tomorrow's concern.

\section{Theme: No investment in digital media education or change management}


A lack of education in digital media fueled a negative feedback loop where nonprofits weren't valuing or investing in digital and so remained uneducated in the area, and so on and so forth. This kept organizational cultures stuck in the past. With little to no ability to re-invest in their people and culture, educational deficits in digital media at all levels of an organization were a significant burden to those who participated. Low recognition and understanding of digital roles internally led to very little investment in furthering digital capacities or competencies from a resource perspective. It also often meant that fighting for priority, or even respect, from other teams or clients and executive members was a hardship, and clear source of stress.

"Raising the profile of digital at our organization was a constant struggle."

"Our ideas were always less important because we weren't running major gifts, or programs."

"I could write a book on digital strategy, or keep teaching it, but I don't often see leaders clamoring to educate themselves on this."

"I think people take us for granted. They see us as this thing that just happens in spite of everything that's going on, so they push off our ideas."

What's more, this educational deficit in digital media at a leadership level led to undue and misplaced pressure on those in digital roles, many of whom shared this experience as part of their contribution to this investigation. This is unsustainable. The meaningful adoption of digital does not supersede other roles, but does require structural, cultural changes within the organization. $50 \%$ of consultant participants identified this as a major problem of meaningful digital adoption. It would mean investment in cultural change management, as well as re-education of their staff, a form of risk that many nonprofits were not well equipped to adopt, let alone afford. 
"I get really frustrated when I read job postings for digital positions clearly written by someone who has no respect or knowledge of that skill set."

"Boards may hire someone to do digital, but they don't appreciate that the whole organization should be thinking digitally."

This was also connected to a talent erosion identified by consultants at organizations who haven't properly adopted and woven digital into their operational fabric. With little resources, low experience, no upward mobility, and no room to advocate for their roles, or even push back when they are expected to do too much for too little pay, talent leaves. They may take with them any meaningful planning and long-term strategy they've tried to build as a result, placing organizations back at square one.

"Digital roles pay so little that people are often inexperienced, they aren't given any growth opportunities, and so the turnover is very high. This prevents digital strategies from being built because no one can oversee them long-term."

\section{Theme: Survival- mode culture.}

Do more with less, and do it in a year.

This was another major theme that emerged from analyzing the problem-discovery interviews. Constant pressure to keep costs low meant that many participants were tasked with the work of two or three people. Their daily tasks were described as so great that they often celebrated just getting through the accomplishments within 8 hours. 
"It's really hard to think strategically and long-term when there's so much to get done today."

"Everyone is doing the role of 2 or 3 people."

"Finding time to focus on bigger-picture planning is difficult."

Additionally, participants often mentioned being evaluated on their performances within a short time frame. In a system where merit is based on funds-in-the-door-today, building towards long-term gain and growth is that much more difficult.

"Focusing on long-term goals doesn't actually add to my appraisal. I'm not measured on it."

"I have to break even on my salary every year because that's how my value is determined."

This leads to a short-term and therefore inaccurate perception of the ROI in stewardship, and very little focus on stewardship and retention as a key performance indicator.

"If someone gave 100 bucks this year, then gave again the following year, no one is going to attribute that to the fundraiser."

"It's harder to fight for a stewardship email than an email that might result in an immediate donation." 
"I think it's just more straightforward to acquire new donors, even if the cost is greater. For example, if I bring in $\$ 300$ of donations this year and the organization spends $\$ 250$ we’ll just break even."

“Trying to get stewardship prioritized is challenging because it doesn't result in 'huge gains'."

\section{Theme: 'Low Investment in Technology'}

A majority of participants mentioned struggles with information and systems siloes, gaps, and inefficiencies that sucked a lot of their time and resources. Again, this is connected to the pressures that nonprofits face to keep their operating costs low. Nonprofits as a result don't invest in their internal technologies and optimizing systems so they integrate. This makes an omnichannel approach to operations, marketing, and stewardship extremely difficult to achieve. In other words, creating and ensuring a consistent, frictionless experience for donors is manually exhaustive and difficult as a result of siloed systems and information. Even simple best-practices like sending timely thank yous were sometimes challenging and resource-heavy.

"We have a DB of record, an email platform, a donation form where the gifts are coming in, and a call center database and none of them are integrated."

"Most of my job is helping donors overcome the barriers put in place by our systems when I should be deepening our relationships with them."

"We're using 3 platforms now to send out all of our e-blasts, so unsubscribing someone from our comms is labour intensive." 
As well, many participants discussed having issues with stale, inaccurate and unreliable information. This often meant a reversion to manual processes because of mistrust in data.

This may, as some stated, be a result of a 'survival-mode' culture which does not, or cannot, invest too much time in protecting data inputs for future benefit. As a result, no one is a custodian of their donor data making the systems which house and interpret that data inaccurate and unreliable.

"Being able to get our data to do our work for us is a challenge. We have problems with duplicate records, we have problems where we only have a workplace address, and that person no longer works there, so we lose that connection."

"The staff have to deal with inputs well, know how to use the database, and value information accuracy for the DB to be optimized, which isn't usually the case.”

"It's hard to make sure we're segmenting our donors correctly when our data is unreliable."

Lastly, there was a lot of difficulty with the systems and platforms themselves. Outside of systems being integrated, there were a lot of identified limitations with logging and extracting information to support relationships with donors. Many participants stated difficulty adapting these databases and platforms for their needs in building relationships with donors as well. This slows these processes which unnecessarily boggeddown stewardship practices at participating nonprofits.

"Figuring out renewal rates in Razor's Edge was a challenge." 
"There's no space in the database to track why a donor gave or other useful anecdotal info that would help build relationships."

"We struggle with using our database for stewardship purposes, like building donor journeys and keeping track of metrics that matter to stewardship. We would like to segment our donors based on their level of engagement and values in order to build out journeys around that. Even if we do keep track of relationship and engagement data, we don't always use it because it's not accessible."

"Razor's Edge was not built with stewardship in mind."

\section{Major Theme: Barriers to Building Good Donor Experiences}

Nearly all of the participants interviewed mentioned the words 'donor journey'. They were all either thinking about their donor journey, trying to build it, or had built it and were actively implementing it. The feeling, synonymously, was that the donor journey was a great start to bringing donors in to the organization and its mission, building a cohesive marketing, branding and stewardship strategy, and improving intelligence on their current donors.

"We hope that having a donor journey will help us understand more about our donors, and how we can upgrade them more easily."

"Defining our donor experience and process will also help us understand what data we need to be recording on our donors to better engage them and deepen relationships."

"As more of our donors become digital first we need to be sure that we have a solid plan to steward them in a digital first way." 
"A good donor journey is the only way for organizations to sustain their relevance in digital."

However, for the participants interviewed, despite the enthusiasm surrounding the donor journey there were many barriers to making this happen in the most efficient way possible. With many points of entry, channels to communicate on, types of donors, in combination with the aforementioned deficit in strategy, talent, and knowledge, this was a daunting task. Experience-building requires coordination of people and technology and this was a challenge for a lot of the participants, especially given the aforementioned 'survival-mode' culture.

"It feels like every channel is so highly specialized and has different tactics and best-practices that creating a cohesive experience across them is very difficult and time consuming."

"Most of our acquisition is done face-to-face so we struggle to know how to engage those people digitally."

"Mapping out a donor journey is complex and difficult when you have 9 channels of entry to consider."

"How do you communicate to people coming in through channels like CanadaHelps and how do you bring them in to the fold?”

"How do you engage people making legacy donations? I would pay a lot of money for someone to tell me how to do that." 
In addition, there was sometimes a lack of sophistication when it came to understanding donors outside of demographics and giving history, leading to low experiential data on donors. Many of the participants expressed wanting to be able to know more about their donors, what inspired them to give, and other valuebased information that would allow them to craft better communications. However, this was sometimes in direct conflict with the way in which they thought about targeting communications, which was often demographically, not experientially focused.

"We're not sure what the right mix of ask and non-ask communications is."

"We have a lot of different kinds of donors so it's difficult to engage them all in the way that they'd prefer."

"We don't want to be guessing, well based on this gift amount and postal code, do we send this?"

"How do we start to put out thankyous and updates that the donor wants to hear?"

"Understanding why a donor gave to us is a real blind spot."

"We don't quite understand who we should be emailing out of our donor lists."

"Our work is very broad so it's valuable to understand why a donor is giving to us."

In relation to good experiences and understanding donors, there were issues with communicating the mission effectively. Creating a healthy funnel requires that the top of the funnel be filled by donors who are properly onboarded to the mission and vision of the organization they opt to support. This was a challenge for many 
of the research participants who stated often that they had difficulty when it came to donor recognition of their impact. This may be due to a variety of factors, but may include low investment in evaluation within organizations, or, in other words, a proper understanding of organizational impact.

"Differentiating ourselves so that our impact is unique is challenging."

"Because our impact is multi-faceted, it's difficult to explain it to the donor."

"We do a lot so it's difficult to communicate our impact to donors, new and existing."

"We are dependent on the trust of our donors, but it's very difficult to communicate the tangible impact of a donation when we're trying to create long-term change.”

"When donor money goes into unrestricted revenue it becomes very difficult to tell them exactly what impact their money had."

There were a few other issues that came up which suggested that communication guidelines prohibited bestpractices in acquisition storytelling as described in Chapter 2 of this paper. In other words, expressing the needs of the benefactor, and the organizational causes were being suppressed by greater digital strategy.

"Our brand guidelines sometimes prohibits us from communicating the needs we are trying to address."

A problem one could speculate, is that acquiring the right donors, in the right place, at the right time would be a difficult feat for a nonprofit lacking experiential data on their donors, and a strategy in which to 
effectively engage them. Of course this all ties back to a lack of good information, and systems in which to manage that information.

All of these problems stem from low operating costs that stifle growth at all of the participating nonprofit organizations. Low operating costs are, again, the most concerning problem and can be connected to all of the problems participants were facing in connection to poor retention at their organizations. Without the ability to invest in sustainable growth, innovation, optimization, talent and technology, nonprofit organizations stay stuck in the past, and much worse, in their inefficiencies. This results in a lot of unintended resource waste, including poor retention of their donors.

\section{Research Question 2: Of the most common problems that prevent nonprofits from improving their retention, which are they actively trying to solve?}

Arriving at the answer to the second research question involved narrowing the data pool down to include

only early adopters, as per step 5 outlined in section 3.2. Early adopters, or potential customers were found by following steps 1-4, which helped to identify early adopters. In this case, and in direct connection to the second research question, early adopters were participants who experienced one of the problem themes outlined in the evaluation of the first research question. These participants knew they had one or more of these problems, and were actively trying to solve them.

Doing this narrowed the pool down to 13 participants, nearly half of the original 27 . In some cases this led to their partial transcripts, audio recordings and notes being referred to and analyzed a third time to extract more insights. When gaps in knowledge were found, participants were sent follow-up questions via email in order to verify their responses and their potential as early adopters. 
Combining existing and fresh insights from these 13 participants, step 5 in the methodology was followed. An affinity diagram was created in the same fashion as described in step 5, section 3.2.

The problem interview exit criteria is as follows: know the demographics of an early adopter, know their biggest problems and how they currently solve them (p.121, Maurya, 2012). Narrowing the data pool lead to satisfying this criteria, as follows:

\section{Demographics of an early adopter:}

Likely working at a larger nonprofit organization, or advocacy-focused organization in a manager or executive role in digital marketing, and/or stewardship and recognition. The organizations they work for likely had fewer barriers in relation to improving retention and had a more progressive culture and way of working.

\section{Potential Problem Worth Solving:}

Challenges Getting and Using Donor Insights.

How they currently solve this problem:

- Donor surveys, with little response success

- Testing content success using quantitative metrics

- Analyzing quantitative data and engagement metrics

- Machine learning solutions to help identify opportunities to upsell, cross sell, save donors, and generate content suggestions based on previous behaviours and/or interactions with previous campaigns and content.

- Optimizing their content for every digital channel, instead of optimizing it for their donors

Of the problems surrounding poor retention, getting and using donor insights is the hypothesized problem worth solving that a select few early adopters, chosen from the greater pool of participants, are actively trying to solve. The insights surrounding this problem provide greater context. 
First, early adopters did not find that their donors were responsive to surveys. They were actively testing ways to get their donors to respond to them for more qualitative data, but in the end was a limiting factor.

"We can only infer what we believe our donors think of our content because we don't hear from a lot of our donors."

“Our donors don't respond to us, so we're left to assume that if 1 person feels this way then 5 others will feel the same."

"Surveys have traditionally low open and response rates, so questions needs to be kept to a minimum which often results in generic, non -specific language and they don't provide a ton of useful info."

Their current strategies to solve this problem were inefficient. They were relying on outside, third party intelligence which offered a generalized profile of donors. They were exhaustively testing content against content to understand what was being engaged with more, and relying on quantitative data and metrics that did not offer a full and complete understanding of donor engagement. In other words, they knew how, if and when their content was being engaged with, but they were not able to understand why their content was working or not working. They weren't able to glean a complete understanding of whether their content was a success without insight as a basis upon which to evaluate their success.

"We will survey donors for the next 6-12 months to understand clusters of motivation for giving, build personas out of that, and tailor our stewardship efforts based on those personas." 
"We A/B test our surveys to donors to see which one is more successful."

"We were looking at open rates and unsubscribes, but now we're trying to look at deeper interactions like click-through rates and conversions (petition signatures etc.). We're also A/B testing who the email comes from, subject lines etc. to see what works better."

"We're inferring a lot from our data about what content is resonating with our donors based on metrics that aren't indicative of behaviour or core values."

“Open rates don't tell me if someone opened the email but didn't read it because we sent it during a busy time of the day and so they forgot about it."

"We assume that when someone gives us money in response to an email it means that they want to hear from us."

This also led to inefficient practices when came time to communicate to donors. Without knowing more insights on how to engage their donors, many early adopters had a tendency to take a shot-gun approach to communicating. The goal was to optimize as best as possible for every channel in the hopes that implementing best practices of each digital channel would be enough to catch or keep the attention of their donors. This is unnecessarily wasteful when it comes to retention especially. If recipients of content are predetermined based on imperfect, and limited information, potential success is severely limited.

"We need to be ever-present so that when the donor's ready for us we're there, but we also don't want to spam them." 
"We often over-send content because we aren't sure what will resonate."

"With current donors we just hope that their awareness of us is high enough that it leaves them more open and receptive to our communications."

Doing so led to many early adopters describing their communications getting lost, or falling on deaf ears.

Without the aid of information and insights on how best to engage donors and break through the noise and competition of digital channels, many early adopters felt this was one of their biggest problems.

"We feel like we're not effectively communicating our impact and mission because donors have misperceptions about what we do all the time."

"We're well known, but not known well."

"We struggle with awareness of what we do, and why we need the help of donors to do it."

"It's tough to get a donor's attention, engage them, AND get them to understand our impact through digital channels because they're so competitive and busy."

\section{Research Question 3: How can a digital solution help them actively solve common problems surrounding poor retention?}

In light of the hypothesized problem worth solving, getting and using donor insights, the task was then to find and test a potential solution to address this problem. 


\section{A competitive audit}

A scan of existing digital products in the area of customer insights was done in order to better understand how a digital product to address donor insights might create unique value in this space and address the hypothesized problem worth solving.

Research into existing solutions in customer insights led to three main competitors, $60 \%$ of whom existed mainly in the for-profit world.

1) Salesforce Customer 360 is a tool that allows companies to unify their fragmented data to create comprehensive customer profiles (Pereira, 2018). It also allows for more advanced segmentation based on these profiles, for example, women interested in buying shoes based on cookie data and purchase history (Pereira, 2018). Many of the participating nonprofits are moving or have moved to this customer relationship management (CRM) platform, and would be able to tap into this tool with the right package.

2) Mailchimp Marketing CRM platform uses data from existing contact lists and campaigns to create a more comprehensive dashboard and analytics features like analyzing lifetime value, building lookalike audiences, advanced tagging and segmentation of their lists, and other basic testing and reporting features (Mailchimp, 2019). It allows users to learn more about their audience demographics and preferences through an audience dashboard feature, and suggests one-click campaigns based on their previous behaviour and buying history. There were a few participating nonprofits using Mailchimp, of whom could easily tap into the features offered through their marketing CRM platform. Mailchimp also has integrations with many other popular nonprofit platforms, which make it an appealing choice (Mailchimp, 2019). 
3) Lastly, smarter tools are popping up in the nonprofit space that allow for a deeper understanding of current donors. For example, Fundmetric is a machine learning engine that offers the latest capabilities of this technology to the nonprofit sector. Fundmetric can mine for interest data and other "overlooked" information that help fundraisers create messages more likely to resonate with their targets (Fundmetric, 2019). Fundmetric also uses predictive analytics to identify when a donor is at risk of lapsing, and other opportunities for upselling or cross-selling donors (Fundmetric, 2019). Algorithms track donor behaviours and reactions to content to recommend the best content for donors, and automate stewardship efforts by recommending what, when and how to communicate with donors (Fundmetric, 2019). They also offer stronger segmentation focused on fundraising opportunities and make best-practices in improving retention automated and easily obtainable (Fundmetric, 2019).

The competition in this problem area offer competent, robust solutions to get and use more donor insights that save resources and power more relevant communications. In order to compete and deliver unique value, a solution to address this potential problem worth solving was hypothesized to have at least the following features and capabilities:

1) Automated donor profiles that are 'live', or updating at the discretion of the user, and offer more insights by making more powerful inferences on a combination of existing and publicly available data.

2) Insight tags that can be integrated with existing nonprofit databases and donor profiles for more meaningful targeting and segmentation.

This feature was only partially supported by the data:

3) Mobile, insight notifications and one-click stewardship messages that are generated based on the profile of a single donor, or group of similar donors, and relationship-building best-practices. 
A video describing the hypothesized problem worth solving, top features and unique value of a solution to address this problem was created as a demo. The following results and feedback were generated from 6 early adopters in response to the hypothesized problem worth solving and solution demo.

\section{The problem is verified by all early adopters.}

Every early adopter identified with the hypothesized problem worth solving.

"We don't know our donors well enough to know what's motivating them, and we don't know who our strongest advocates are because we don't have the capacity to look for those behaviours and how they're responding to our messaging."

"How do we quantify 'super engaged'? What does a donor do that makes them super engaged? We've tried to do that to figure out who our super engaged donors are."

"We have $100 \mathrm{k}+$ donors and supporters so it just isn't reasonable for us to know them all individually."

\section{Some hypothesized features delivered on unique value.}

The value they felt this delivered supported a few of the hypothesized, unique features outlined above. Easily understanding their relationship with the donor outside of donations was identified as being very valuable, in addition to identifying highly engaged constituents and feeling confident that their information wasn't stale or inaccurate. They also felt that if it could deliver on seamless integration with their existing platforms and data, 
and tag their current donors with insights and platforms to make segmentation more meaningful, that would also be very valuable.

"We often don't know why people are giving so that would be really useful."

"I like that it would tell me a bit more about how our donors are interacting with us outside of volunteering and donating, because that's only a very small part of the picture."

"Donations is only one side of a donor's commitment to you, so understanding the other side of their commitment to you would be powerful."

"I'm currently trying to profile my donors, but I haven't seen a solution that helps me implement the profiles."

A few early adopters identified the one-click features as an "interesting way to implement the insights in stewardship efforts", but this feature was not supported by all 6 as a crucial part of the value of this product.

\section{Privacy, protection and other data concerns were a huge barrier.}

Many early adopters felt they would need more assurances on how the data would be used and protected. They were wary of protecting their donor's privacy and didn't want to overstep, or misstep, by communicating to donors in a way that would be considered invasive, or "big brother"-like.

"We can't just send our data out to a new platform, we'd have to explain this to our donors." 
"What about CASL and other regulations? How do you get around those?"

"Would like to know how data is protected, and the privacy of our donors."

\section{Suggestions were made around change management and acquisition features.}

A few early adopters, some of whom are using competitive products, would like to have seen how the solution would support change management within their organizations. They felt this would be an added bonus and would help maximize investment in such a solution.

"If you can include some change management in there that would be huge. This is what it will look like for you in the future. These are the steps that you'll go through. This is where you'll see shortterm gains for longer term goals."

"The problem is that we work in such siloes that getting everyone to collaborate on the best possible experience for the donor and engaging them on various levels requires collaboration. It's change management as much as it is the adoption of a new product."

There were also many suggestions to make this into a more insightful prospect research tool, using existing donor profiles armed with why donors were giving, and their level of engagement. Many early adopters asked how this could be used for more powerful prospecting and predictive opportunity generation.

"Knowing the reason my existing donors are giving to me, what donors are we missing out on? I would really like to know if there are opportunities that come out of knowing our donors better on the acquisition side of things." 
"Prospect research — HOW to engage valuable prospects at a major level. We do this manually now, but it would be a great research tool for them at this level of giving."

Barriers to adoption were understanding the commitment in resources the solution requires, and seeing results quickly in order to justify the investment to donors and the board.

"I wouldn't be able to add resources, so the question is, does a new tool free up enough resources, or bring in enough money for me to be able to commit to it?”

"If I do this I'd want to know how many resources I'd need to commit to it to make sure I'm getting the best ROI."

"I'd need to know within the year if it's moving the needle, so I can justify the purchase to my donors and the board."

In the end, every early adopter said they would try it, with one saying they would pay a monthly fee of $\$ 300$ for the solution.

This supports the hypothesized problem worth solving. Problem-solution fit has been found, and an answer to the final research question achieved.

A digital solution which has at least these features...

1) Automated donor profiles that can be "live", or constantly updating, and will create more powerful insights by making inferences on existing and public data that tell fundraisers why a donor gave to 
them, how engaged they are with the organization based on interactions and advocacy behaviours, and suggest opportunities for further engagement as well as solicitation.

2) Integrate with nonprofit databases and platforms to tag donors with insights and profiles that would allow them to segment and target more meaningfully.

is a viable solution to the problem worth solving — getting and using donor insights.

\section{References}

Batra, M. M. (2018). Designing a holistic customer experience program. Competition Forum,16(1), 73-81.

Bennett, R. (2009). Regret and satisfaction as determinants of lapsed donor recommencement decisions. Journal of Nonprofit \& Public Sector Marketing, 21(4), 347-366. doi:10.108 0/10495140802662531

Blank, S. G., \& Dorf, B. (2012). The startup owner's manual. vol. 1: The step-by-step guide for building a great company K\&S Ranch, Inc.

Boenigk, S., \& Helmig, B. (2013). Why do donors donate?: Examining the effects of organizational identification and identity salience on the relationships among satisfaction, loyalty, and donation behavior. Journal of Service Research, 16(4), 533-548. doi:10.1177/1094670513486169

Bullard, O., \& Penner, S. (2017). A regulatory-focused perspective on philanthropy: Promotion focus motivates giving to prevention-framed causes. Journal of Business Research, 79, 173-180. doi:10.1016/j.jbusres.2017.06.013

Burk, P. (2013). Donor-Centered Fundraising (2nd ed.). Hamilton, ON: Cygnus Applied Research, Inc. 
CanadaHelps. (2018). The Giving Report 2018(Rep.). Retrieved https://www.canadahelps.org/en/the-givingreport/?gclid=Cj0KCQjwhJrqBRDZARIsALhp1WQ19egqeDZdGM3fb74qyY4Lyv5ChVAz4Svnu pdR8ISMDzOI01ZsIwEaAtT4EALw_wcB\&gclsrc=aw.ds

Emmett, B. (2016, October 16). Charities, Sustainable Funding and Smart Growth: Discussion Paper. Retrievedhttp://www.imaginecanada.ca/sites/default/files/imaginecanada_charities_sustainability_ smart_growth_2016_10_18.pdf

Fundmetric. (2019). Fundmetric. Retrieved July 26, 2019, from https://www.fundmetric.com/

Kiran, D. R. (2017). Total quality management: Key concepts and case studies. Amsterdam: ButterworthHeinemann is an imprint of Elsevier. doi:https://doi.org/10.1016/B978-0-12-811035-5.00021-0

Kiva.org. (2019). Retrieved March, 2019, from https://www.kiva.org/about/impact

Lasby, D., \& Barr, C. (2018). 30 Years of Giving in Canada The Giving Behaviour of Canadians: Who gives, how, and why? (Rep.). Retrieved http://www.imaginecanada.ca/30years

Levis, B., Miller, B., \& Williams, C. (2018, December 4). The 2018 Fundraising Effectiveness Project report (Rep.). Retrieved http://afpfep.org/reports/download/

Mailchimp. (2019). Mailchimp as a Marketing CRM. Retrieved July 26, 2019, from https://mailchimp.com/features/crm/

Manner-McLarty, A. (2017). Journal of Donor Relations \& Stewardship. Developing Evidence-based Practice within Donor Relations and Stewardship, 1-21. Retrieved from http://www.journaldrs.com/

Maurya, A. (2012). Running Lean (2nd ed.). Sebastopol, CA: O'Reilly.

Maurya, A. (2017, August 17). Find Better Problems Worth Solving with the Customer Forces Canvas. Retrieved July 26, 2019, from https://blog.leanstack.com/the-updated-problem-interview-scriptand-a-new-canvas-1 e43ff267a5d 
McCormick, J. (2016, November 2). Predictions 2017: Artificial Intelligence Will Drive The Insights Revolution (Rep.). Retrieved https://www.forrester.com/report/Predictions 2017 Artificial Intelligence Will Drive The Insights Revolution/-/E-RES133325\#

Merchant, A., Ford, J. B., \& Sargeant, A. (2010). Charitable organizations' storytelling influence on donors' emotions and intentions. Journal of Business Research, 63(7), 754-762. doi:10.1016/j.jbusres.2009.05.013

Moore, G. A. (1999). Crossing the chasm: Marketing and selling high-tech products to mainstream customers (Rev. ed.) HarperBusiness.

Nielsen, J. (2000, March 19). Why You Only Need to Test with 5 Users. Retrieved July 26, 2019, from https:/ www.nngroup.com/articles/why-you-only-need-to-test-with-5-users/

O'Connor, T. (2016). Improving nonprofit donor retention through dialogue (Order No. 10252574). Available from ProQuest Dissertations \& Theses A\&I; ProQuest Dissertations \& Theses Global. (1855626409). Retrieved from http://ezproxy.lib.ryerson.ca/login?url=https://search-proquestcom.ezproxy.lib.ryerson.ca/docview/1855626409?accountid=13631

Oppenheimer, D. M. (2015). Increasing Donations and Improving Donor Experiences: Lessons From Decision Science. Policy Insights from the Behavioral and Brain Sciences, 2(1), 203-210. https://doi.org/10.1177/2372732215600884

Pereira, R. (2018, September 25). What is Salesforce Customer 360? Retrieved July 26, 2019, from https://www.salesforce.com/blog/2018/09/what-is-salesforce-customer-360.html

Peppers, D., \& Rogers, M. (2017). Managing customer experience and relationships: A strategic framework (Third ed.) John Wiley \& Sons, Inc.

Poutonnet, P. (2017, April 12). Survey says: Machine learning happening now and paying off | Google Cloud Blog. Retrieved from https://cloud.google.com/blog/products/gcp/survey-says-machine-learninghappening-now-and-paying-off

Ransbotham, S., \& Kiron, D. (2018, January). Using Analytics to Improve Customer Engagement (Rep.). Retrieved http://sloanreview.mit.edu/analytics 2018

Salesforce. (2019). Nonprofit Trends Report(Rep.). Retrieved https://www.salesforce.org/nonprofit/nonprofit-trends-report-download/ 
The Conference Board, Inc. (2017). 25 truths about customer experience: Insights from the 2017 customer experience conference The Conference Board, Inc.

Utley, T. (2016, September 14). Meet Yeshi, A Bot Launched By Lokai And Charity: Water To Bring Awareness To The Water Crisis. Retrieved July 26, 2019, from https://www.forbes.com/sites/toriutley/2016/09/14/meet-yeshi-a-bot-launched-by-lokai-andcharity-water-to-bring-awareness-to-the-water-crisis/\#25f464962d04 